Gerión. Revista de Historia Antigua

ISSN: 0213-0181

https://dx.doi.org/10.5209/geri.74792

\title{
Las inscripciones del "mausoleo de los Pompeyos" de Torreparedones (Baena, Córdoba). Apuntes sobre las relaciones familiares ${ }^{1}$
}

\author{
José Beltrán Fortes ${ }^{2}$
}

Recibido: 5 de junio de 2020 / Aceptado: 22 de octubre de 2020

Resumen. La serie de doce inscripciones sepulcrales grabadas en urnas pétreas del "mausoleo de los Pompeyos" (Torreparedones, Baena, Córdoba), aparecidas en 1833, constituye sin duda el testimonio epigráfico más completo y significativo del proceso de incorporación a la ciudadanía romana y latinización onomástica en Hispania. Del análisis de la documentación generada por Aureliano Fernández-Guerra en 1834 se plantea una nueva hipótesis sobre las relaciones familiares de los individuos citados en ellas, estableciendo como hipótesis un nuevo stemma de la familia Pompeia.

Palabras clave: epigrafía hispanorromana; onomástica latina; urnas.

\section{[en] Inscriptions from the "Pompeii Mausoleum" of Torreparedones (Baena, Córdoba). Notes on Family Relationships}

\begin{abstract}
The set of funerary inscriptions from the "Pompeii mausoleum" (Torreparedones, Baena, Córdoba), engraved on twelve stone urns and discovered in 1833, are indeed the most complete and significant epigraphic record on the incorporation process into Roman citizenship and onomastic Latinization in Hispania. Starting from the analysis of Aureliano Fernández-Guerra's study, carried out in 1834, a new proposition concerning the family relationship of each person of the gens Pompeia named on them is presented, establishing a new stemma of the familia Pompeia as a hypothesis.

Keywords: Hispano-Roman Epigraphy; Latin Onomastics; Urns.

Sumario: 1. Introducción. 2. Descripción de las urnas y de las inscripciones. 3. Propuestas de relaciones familiares: P. Mérimée, E. Hübner, M. Rodríguez de Berlanga. 4. Propuesta de relaciones familiares a la luz de los datos aportados por A. Fernández-Guerra. 5. La datación de las urnas. 6. Conclusiones. 7. Referencias bibliográficas.
\end{abstract}

Cómo citar: Beltrán Fortes, J. (2021): Las inscripciones del "mausoleo de los Pompeyos" de Torreparedones (Baena, Córdoba). Apuntes sobre las relaciones familiares, en Gerión 39/1, 265-294.

\footnotetext{
1 Trabajo realizado en el marco de las actividades de investigación del grupo consolidado HUM 402, adscrito al Departamento de Prehistoria y Arqueología de la Universidad de Sevilla, dentro del Plan Andaluz de Investigación; así como a los resultados del proyecto de investigación HAR2017-89004-P, aprobado por el Ministerio de Economía y Competitividad de España, Plan Estatal 2013-2016 Excelencia - Proyectos I + D, y subvencionado con Fondos Feder.

2 Universidad de Sevilla.

E-mail: jbeltran@us.es

ORCID: 0000-0001-5841-4140
} 
Stemma Pompeiorum horum redintegrare studerunt... sed praeter aperta quaedam nihil certi expediverunt ${ }^{3}$

\section{Introducción}

En el año 1844 salía a la luz, en el tomo I de la Revue Archéologique, un interesante estudio del hispanista francés Prosper Mérimée (1803-1870) sobre las inscripciones del sepulcro o mausoleo "de los Pompeyos", que tituló escuetamente como "Inscriptions Romaines de Baena". ${ }^{4}$ Se trataba de un descubrimiento excepcional que había tenido lugar once años antes, en 1833, en tierras del término municipal de Baena (Córdoba); así, el día 16 de agosto un vaquero que cuidaba el ganado en el cortijo entonces llamado "de las Vírgenes" denomina Torreparedones $-^{6}$ descubrió ocasionalmente la cámara de un mausoleo romano con diversos materiales arqueológicos. El arrendador de aquellos terrenos, Diego de Pineda, logró reunir la mayor parte de ellos, entre los que sobresalían, amén de los ajuares y una urna de vidrio dentro de un recipiente plúmbeo, catorce urnas de piedra local caliza, con tapaderas del mismo material; doce de ellas tenían otras tantas inscripciones latinas grabadas en sus respectivas cajas, mientras que dos eran anepigráficas, ${ }^{7}$ aunque contenían cenizas. ${ }^{8}$ Por ejemplo, la noticia se recogía del siguiente modo en el Boletín Oficial de la Provincia de Córdoba, $\mathrm{n}^{\mathrm{0}} 34$, de 5 de septiembre de ese mismo año de $1833:^{9}$

El 16 del corriente los sirvientes de D. Diego de Pineda descubrieron una bóveda subterránea en las tierras del Cortijo llamado de las Vírgenes, situado al N. de esta $V .{ }^{a}(\ldots)$ dentro del cual hayaron, según manifestación que los mismos han hecho, doce urnas de piedra labrada con inscripciones Romanas (...) tambien se halló un vaso grande de vidrio, dentro de una funda de plomo, que según se advierte es de inferir fuese una lámpara, cuyo vaso está quebrado (...) además se encontraron unos jarritos de barro de figura estraña, que es presumible pusiesen en la bóveda con las Urnas (...) que dhas Urnas contenian cenizas, que fueron derramadas en el acto de encontrarlas por los hombres rústicos que las hallaron (...) y porción de huesos calcinados. La bóveda o Panteón subterráneo (...) alrededor tenia una cornisa de piedra de una tercia de ancho $\mathrm{q} .{ }^{\mathrm{e}}$ era donde se

CIL II $\mathrm{II}^{2} / 5,114$.

Mérimée 1844; también reproducido en Maier Allende - Beltrán Fortes 2010, 280-283.

5 Ese nombre era referente a las mártires "cordobesas" de mediados del siglo IX d.C. Nunilo y Alodia, para las que en el siglo XVII se había construido una ermita en aquellos terrenos; precisamente ha sido localizada arqueológicamente en fecha reciente y comprobado que se construyó reutilizando los restos de unas termas romanas (Morena 2019).

6 En el marco de los trabajos de excavación dirigidos por B. W. Cunliffe y $\mathrm{M}^{\mathrm{a}} \mathrm{C}$. Fernández Castro en la década de 1980 se empleó el topónimo de Torreparedones para referirse al yacimiento (Cunliffe - Fernández Castro 1999; Fernández Castro - Cunliffe 2002), y así se conoce ya en el ámbito científico, por lo que continuamos usando ese topónimo. Sobre el yacimiento vid. la síntesis en Márquez et alii 2014.

7 Se ha dicho también que pudieran haber llevado tituli picti (Amela Valverde 2011, 29); no hay constancia de ello, aunque es probable, dado además que una de las urnas inscritas tenía restos de un titulus pictus, como se verá.

8 Maier Allende - Beltrán Fortes 2010, 255, según referencia de Aureliano Fernández-Guerra.

9 Reproducido en Maier Allende - Beltrán Fortes 2010, 229-230. 
hallaron las doce Urnas (...) La simple lectura de estas inscripciones es suficiente para convencerse de lo absurdas q. ${ }^{\text {e }}$ han sido la mayor parte de las noticias que acerca de este descubrimiento han circulado (...) Tambien es de nuestra noticia que se solicita por cierta persona, bastante instruida y aficionada á antigüedades, el permiso para hacer algunas excavaciones en los alrededores del sitio en que ha sido descubierto el Sepulcro; y desearemos que por parte de los dueños del terreno no se pongan obstáculos a una empresa que tanto puede ilustrar, y de que tan conocidas ventajas pueden sacarse. ${ }^{10}$

A este tema hemos dedicado una obra colectiva, publicada en 2010, en la que se lleva a cabo el análisis arqueológico de la tumba y de los ajuares, el estudio epigráfico de las inscripciones, así como la valoración historiográfica de la extensa documentación escrita y gráfica que generó en el siglo XIX en España. ${ }^{11}$ Ello se debió a que, entre las inscripciones de las urnas, había varias referidas a difuntos pertenecientes a la gens Pompeia y, en un primer momento, se sostuvo que era la tumba de uno de los hijos de Pompeyo el Grande, en concreto de su hijo Cneo, así como otra con la inscripción Gracchi, que también se puso en relación con los Sempronios Gracos. Es sabido que Cneo Pompeyo el Joven murió en Hispania, semanas después de la batalla de Munda, ${ }^{12}$ y diversos eruditos españoles de la época, relacionados con el descubrimiento, como Diego de Padilla, José María Jurado, José Manuel de Arjona, José María de Rodas o Juan Jurado Valdelomar, interpretaron que esta era la tumba familiar de aquel; los informes y estudios asimismo se publicaban en diarios locales y nacionales, como prueba del interés que despertó el descubrimiento. ${ }^{13}$

La Real Academia de la Historia, dada su encomienda tutelar sobre las antigüedades de España, recibió todo tipo de informaciones, de eruditos y próceres locales, mediante cartas e informes, y formó una comisión para dictaminar sobre el hecho, lo que ha generado un amplio expediente en su archivo. ${ }^{14} \mathrm{El}$ informe final lo firman los académicos José de la Canal y Félix Torres Amat el 4 de octubre de 1833, recomendando, de manera acertada, que se ampliara y testimoniara el descubrimiento, documentando las inscripciones y con dibujo de ellas, de las urnas y del resto de ajuares, a la vez que recabando información de los descubridores y de aquellos que visitaron la tumba. ${ }^{15}$ Es significativo que se aceptara la existencia de una "lámpara de luz inextinguible", que se habría apagado al entrar la luz natural en la cámara y que no era más que el resplandor de la urna de vidrio dentro de su funda de plomo; enlazaba ello con la tradición italiana, espuria, de que una lámpara similar había sido descubierta en la tumba de la hija de Cicerón, Tulia, y que había transmitido, por ejemplo, en la centuria anterior, el padre Feijoo. ${ }^{16}$

10 No sabemos qué persona era la que quería excavar el sepulcro, pero tampoco se hizo y sus restos quedaron olvidados (Beltrán Fortes 2000), hasta que en prospecciones geofísicas realizadas en 2008 se ha localizado muy probablemente el lugar donde está la tumba, si bien no ha sido explorado aún (Morena López 2010, 191-202). En este texto se menciona "la bóveda" porque la cámara sepulcral se cubría con una bóveda de medio cañón y posiblemente era semihipogea.

Beltrán Fortes et alii 2010; para el apéndice documental, Maier Allende - Beltrán Fortes 2010, 209-354.

Amela Valverde 2000.

Todas esas referencias están reproducidas convenientemente en Maier Allende - Beltrán Fortes 2010.

Maier Allende - Beltrán Fortes 2010, 222-241.

Cit. en Maier Allende - Beltrán Fortes 2010, 237.

Feijoo 1730, discurso tercero, párrafos I-XIII. 
Frente a la enorme repercusión nacional, solo el artículo de P. Mérimée refleja un interés allende las fronteras patrias en aquellos momentos, que viene justificado, por un lado, por el carácter de hispanista del arqueólogo francés, así como, por otro, por el excepcional documento que constituían las inscripciones para explicar el proceso de "romanización", aplicable asimismo a la Galia, aunque con un planteamiento propio de la época. Así, afirmaba P. Mérimée: "Dans toutes le provinces de l'empire, les habitants barbares prirent de bonne heure des patrons parmi les conquérants et adoptèrent leurs noms, empressés de faire oublier leur origine et de s'affilier à la nation souveraine". ${ }^{17}$

El artículo del estudioso francés se centraba, pues, en las inscripciones de las urnas, entre las que destacaba las cinco correspondientes a los miembros de la familia Pompeia, "ce sont vraisemblablement les plus modernes", y la de Fabia Aninna, "dont le nom rapelle celui de Q. Fabius Maximus, lieutenant de César en Espagne". ${ }^{18}$ También justificaba el nombre de Iunia Insghana en relación a varios Iunii romanos presentes en Hispania, así como el de Gracchus por la presencia de los Sempronios Gracos en el territorio hispano. Concluía "que la tombeau de Baena aurait été construit à une époque postérieure à la guerre civile de Pompée et de César, et probablement une ou deux générations après cette lutte mémorable". ${ }^{19}$ Habrá que esperar a 1861 para que, con base en la interpretación de P. Mérimée y de otra llevada a cabo por Manuel Rodríguez de Berlanga, ${ }^{20}$ que mencionaremos más adelante, Emil Hübner realice el que ha sido considerado como el mejor estudio de esas inscripciones editado durante el siglo XIX. ${ }^{21}$

\section{Descripción de las urnas y de las inscripciones}

En la documentación más o menos coetánea del descubrimiento se encuentran algunos ingenuos dibujos de las urnas y de los ajuares ${ }^{22}$ pero sin duda las mejores representaciones son las que realizó en 1834 el joven -por entonces- Aureliano Fernández-Guerra (1816-1894), ${ }^{23}$ aunque lamentablemente quedaron inéditas. ${ }^{24}$ Esos apuntes y dibujos fueron plagiados poco después por Manuel de la Corte y Ruano (1816-1852) -nombrado en 1838 inspector de antigüedades de Andalucía por la Real Academia de la Historia- ${ }^{25}$ y publicados en el año 1839 en varios fascículos del Semanario Pintoresco Español;26 ello dio lugar a una encendida polémica entre ambos, con réplicas y contrarréplicas que se dieron a la imprenta, pero no nos cabe duda de que el plagio existió.

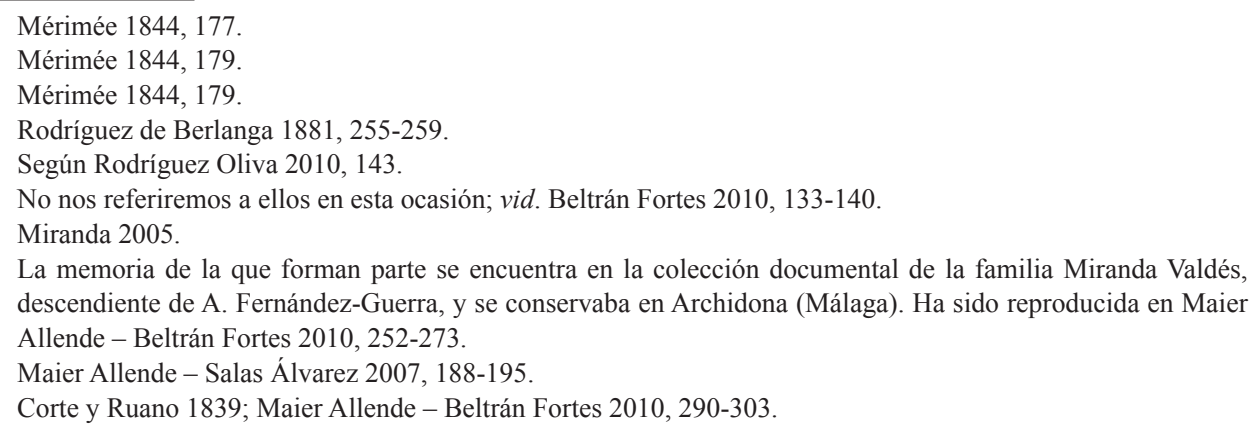


A pesar del interés de la Real Academia de la Historia para su traslado a Madrid, las urnas y el resto de materiales arqueológicos permanecieron en Baena, según testimonia Francisco Valverde y Perales, quien publica las primeras fotografías de las urnas a comienzos del siglo $\mathrm{XX}^{27}$ (Fig. 1); además, este autor indica que, muerto el primer propietario, Diego de Pineda, la colección se había repartido entre las dos hijas, quedando una con ocho urnas de piedra y la de cristal con funda de plomo y la otra con cuatro.

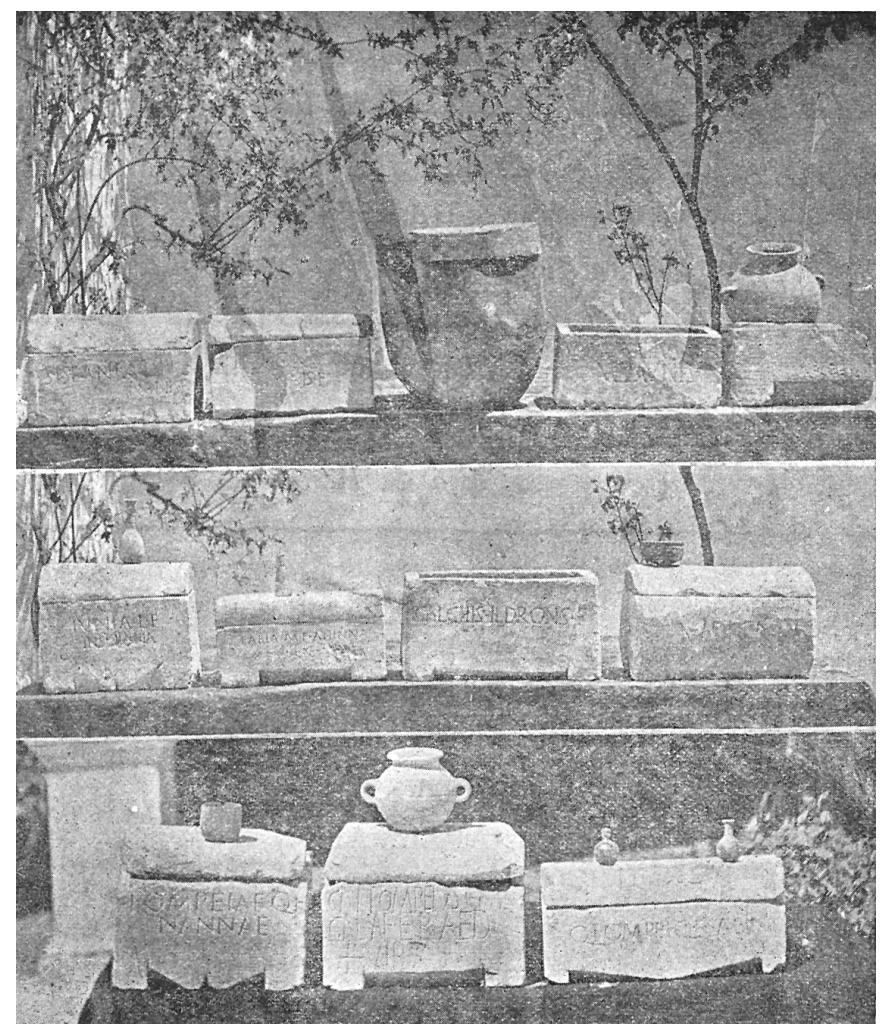

Fig. 1. Fotografía de las urnas y ajuares del mausoleo de los Pompeyos, de Torreparedones (Valverde y Perales 1903, 40, fig. 12)

En el montaje fotográfico de la lámina de su libro se disponen, en la parte superior, de izquierda a derecha, las urnas de Sisean y de Ildrons, el contenedor de plomo, la urna de $Q$. Pompeius Velaunis y otra que debe ser anepigráfica, pues no se corresponde con ninguna de las dos que faltan, como se dirá a continuación; en la parte central de la fotografía se reconocen las urnas de Iunia Insghana, Fabia Aninna, Igalghis y Velgana; finalmente, en la parte baja, se disponen las urnas de Pompeia Nanna, Cn. Pompeius Afer y Q. Pompeius Sabinus. No están fotografiadas, pues, las de M. Pompeius Icstnis y de Gracchus. Es por ello que, según se dirá a continuación, también de estas dos urnas no hay copias en yeso, pero tampoco de las de Fabia Aninna, Iunia Insghana e Ildrons, que sí aparecen en las fotografías.

27 Valverde y Perales 1903; también reproducido en Maier Allende - Beltrán Fortes 2010, 285-289. 
E. Hübner, cuando visitó Baena durante su viaje por España entre los años 18601861 , vio personalmente solo tres urnas, ${ }^{28}$ pero, como se ha dicho, en un momento impreciso del último cuarto del siglo XIX o comienzos del siglo $\mathrm{XX}^{29}$ se obtuvieron copias en yeso de siete de ellas para el recién creado Museo Arqueológico Nacional, en cuyos almacenes se conservan aún hoy día; esta serie ha sido editada, estudiada y confrontada con los dibujos de A. Fernández-Guerra por Pedro Rodríguez Oliva, ${ }^{30}$ quien, además, se ha ocupado de manera más general en varias ocasiones del análisis del uso en la Hispania meridional de este tipo de urnas de piedras locales, areniscas y calizas, durante la segunda mitad del siglo I a.C. y el siglo I d.C. ${ }^{31}$

Una aportación fundamental que llevó a cabo A. Fernández-Guerra en 1834 fue la de situar las urnas tal como estaban colocadas en la cornisa o poyete de la cámara sepulcral, ya que, según dice: "Yo he descubierto el órden con que estaban colocadas, ya guiándome por las medidas ya por los vestigios que estas dejaron en la superficie de la cornisa (...) El órden (...) es empezar por la derecha del que entra por la puerta del Panteón". ${ }^{32}$

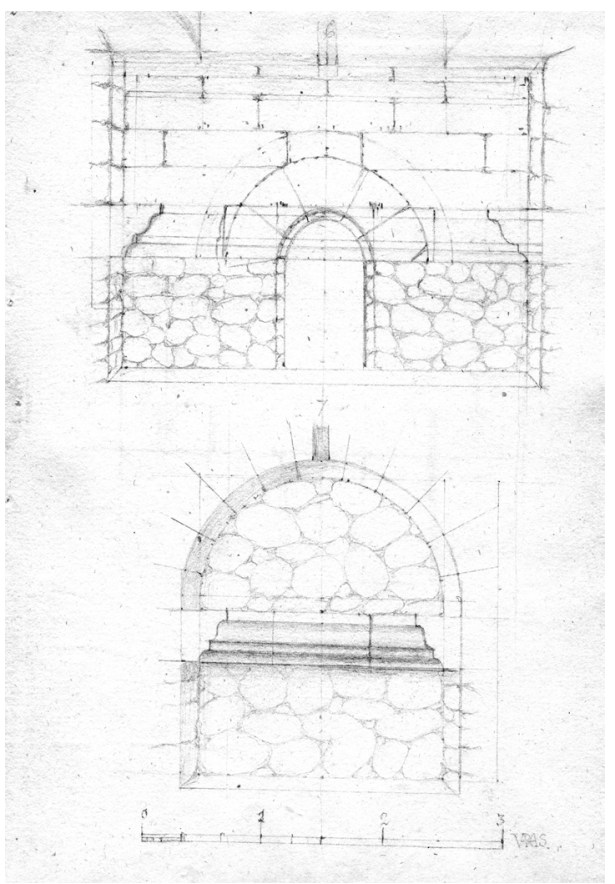

Fig. 2. Dibujos de las secciones verticales N-S y E-O del mausoleo de los Pompeyos, realizados por A. Fernández-Guerra, en 1834. Colección familia Miranda Valdés

(Maier - Beltrán 2010, 254)

${ }_{28}$ CIL II, p. 214: “... mihi monstratae sunt a Pinedae heredibus tres tantum arcae, reliquae celatae invidia quadam stolida". Se trata de las de Fabia Aninna, Pompeia Nanna y Iunia Insghana, cuyos textos recoge también Hübner en los Exempla 43a-c (véase Hübner 1885; en adelante citado siempre como Exempla).

29 Quizás la fecha del montaje fotográfico de F. Valverde pueda servir de referencia cronológica, ya que en ella aparecen tres urnas más de las copiadas en yeso, pero, aunque el libro fue editado en 1903, realmente no sabemos cuándo se hicieron las fotografías.

30 Rodríguez Oliva 2010, 152-157.

31 Rodríguez Oliva 1993-1994; 1999; 2001; 2002.

32 Cit. en Maier Allende - Beltrán Fortes 2010, 255; Rodríguez Oliva 2010, 149-150. 
La ordenación tiene relación con sus dibujos de la tumba: dos secciones (Fig. 2) y una planta de la sección horizontal del mausoleo a la altura de la repisa o poyo, indicando las urnas con números (Fig. 3); se observa en ese dibujo que la entrada se sitúa al oeste, faltando el saliente o repisa en gran parte de ese lado, pero se sitúa corrido en los otros tres lados, los dos menores y el mayor oriental, que debía ser el principal, enfrentado a la puerta. No se indica qué ocupaba los dos espacios numerados con 0 , en las esquinas noreste y sureste, ni tampoco en el espacio marcado con la letra A, en el centro del lado norte; en algunos de esos otros espacios quizás se situarían las dos urnas pétreas anepigráficas y la urna de vidrio con su cubierta plúmbea. En resumen, numera doce puestos que corresponden a las doce urnas epigráficas.

Fig. 3. Planta del mausoleo de los Pompeyos con la numeración de la colocación de las urnas, realizada por A. Fernández-Guerra, en 1834. Colección familia Miranda Valdés (Maier - Beltrán 2010, 254)

En otro dibujo parcial del interior de la cámara, que editó el antes referido M. de la Corte y Ruano, en 1839, se advierte una serie de cinco urnas dispuestas sobre la repisa de uno de los laterales ${ }^{33}$ (Fig. 4); así, se suceden, de izquierda a derecha, una olla cerámica con asas y las urnas pétreas de Cn. Pompeius Afer, Fabia Aninna, Q. Pompeius Sabinus, Pompeia Nanna y Iunia Insghana, colocando en la esquina el recipiente plúmbeo, interpretado como "lámpara de luz inextinguible" y, a continuación, en la siguiente parte de la repisa, la urna pétrea de Q. Pompeius Velaunis. Pero ello no es nada fiable, como también le acusó el propio A. Fernández-Guerra: "En cuanto á las

33 Maier Allende - Beltrán Fortes 2010, 294. 
copias de las urnas, para descargo de mi conciencia debo decir que se las di [a Corte y Ruano] en real, y hubo de merecer (...) se las pusiese románticamente en perspectiva"; 34 es decir, que el dibujo en perspectiva publicado por M. de la Corte y Ruano había sido una composición inventada, que, como se verá, no se corresponde con el orden establecido por A. Fernández-Guerra, que es la fuente original.

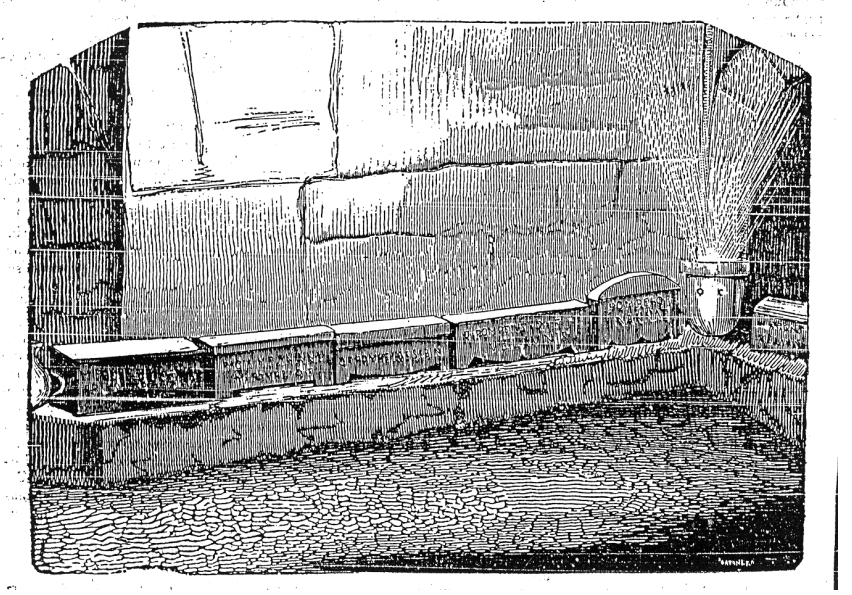

Fig. 4. Reconstrucción idealizada del interior de la cámara del mausoleo de los Pompeyos (Corte y Ruano 1839, 356)

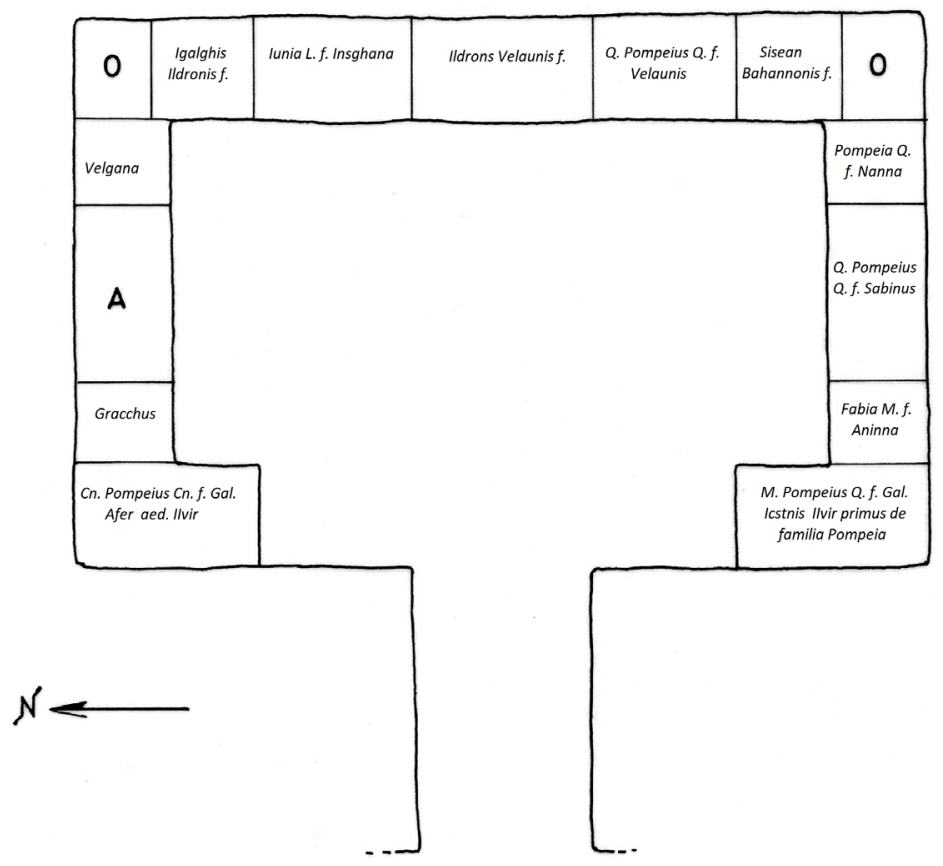

Fig. 5. Propuesta de la colocación de las urnas en la cámara, según datos de A. FernándezGuerra (elaboración propia; dibujo: Elisabet Conlin)

34 Maier Allende - Beltrán Fortes 2010, 331. 
En efecto, como ya se dijo, la colocación de las urnas la dedujo A. Fernández-Guerra al medir sus dimensiones y contrastarlas con las huellas que aún se conservaban en la repisa. Lo dispone mediante una serie de 12 números que corresponden a las diversas urnas epigráficas, pero asimismo refiere cada una de ellas con otra numeración. El autor no justifica esa doble numeración, pero nos parece evidente que la correcta es la más reciente, como ya planteamos en el trabajo de $2010 .{ }^{35}$ Del hecho de que la segunda numeración corresponda con la dada a las láminas de sus dibujos de las urnas, podemos deducir que -en un primer momento- hizo los dibujos sin seguir el orden de las piezas en la repisa de la cámara sepulcral y, posteriormente, advertido el hecho y con la numeración correcta, acompañó la referencia a la urna en la cámara con el número de orden dado en los dibujos. Nos parece una explicación lógica, por lo que planteamos que la numeración correcta es la que incluimos en la restitución de la planta (Fig. 5).

Así, la colocación correcta de las urnas, ordenadas desde la situada a la derecha de la entrada, en la esquina suroeste, es la siguiente (indicamos entre corchetes la referencia al número del dibujo de cada urna según A. Fernández-Guerra, que solo en algunos casos es coincidente):

En la esquina suroeste:

$\mathrm{N}^{\mathrm{o}} 1: M \cdot$ Pompeius $\cdot Q \cdot f \cdot G a l \cdot$ Icstnis /II $\cdot$ vir $\cdot$ primus $\cdot$ de familia / Pompeia [dibujo $\mathrm{n}^{\circ} 1$ ].

En el lado sur:

$\mathrm{N}^{\mathrm{o}}$ 2: Fabia $\cdot M \cdot f \cdot$ Aninna $/ M \cdot$ Pompei $\cdot Q \cdot f$ [dibujo $\left.{ }^{\mathrm{o}} 2\right]$.

$\mathrm{N}^{\circ}$ 3: $Q \cdot$ Pompei $\cdot Q \cdot f \cdot$ Sabini [dibujo no 3 ].

$\mathrm{N}^{\mathrm{o}}$ 4: Pompeiae $\cdot Q \cdot f /$ Nannae [dibujo $\mathrm{n}^{\mathrm{o}} 4$ ].

En el lado este (principal):

$\mathrm{N}^{\mathrm{o}}$ 5: Sisean $\cdot$ Bahan/nonis $\cdot f$ [dibujo $\left.\mathrm{n}^{\mathrm{o}} 10\right]$.

$\mathrm{N}^{\mathrm{o}}$ 6: $Q \cdot$ Pompeius $\cdot Q \cdot f /$ Velaunis [dibujo $\mathrm{n}^{\mathrm{o}} 5$ ].

$\mathrm{N}^{\mathrm{o}} 7$ : Ildrons / Velaunis $\cdot f$ [dibujo $\left.\mathrm{n}^{\mathrm{o}} 6\right]$.

$\mathrm{N}^{\mathrm{o}}$ 8: Iunia $\cdot L \cdot f /$ Insghana [dibujo ${ }^{\circ} 9$ ].

$\mathrm{N}^{\mathrm{o}}$ 9: Igalghis $\cdot$ Ildronis $\cdot f$ [dibujo $\mathrm{n}^{\mathrm{o}} 7$ ].

En el lado norte:

$\mathrm{N}^{\mathrm{o}}$ 10. Velgana [dibujo $\mathrm{n}^{\mathrm{o}} 11$ ].

$\mathrm{N}^{\mathrm{o}}$ 11: Gracchi [dibujo no 8].

Entre ambos se marca el espacio central con la letra A, que no sabemos a qué corresponde.

En la esquina noroeste:

$\mathrm{N}^{\mathrm{o}}$ 12: Cn $\cdot$ Pompeius $\cdot \mathrm{Cn} \cdot \mathrm{f} / \mathrm{Gal} \cdot$ Afer $\cdot$ aed $\cdot /$ II vir [dibujo ${ }^{\mathrm{o}} 12$ ].

En la urna $\mathrm{n}^{\mathrm{o}} 1$ se ha grabado $M($ arcus $) \cdot$ Pompeius $\cdot Q($ uinti) $\cdot f($ ilius $) \cdot G a l($ eria $)$ - Icstnis / II · vir · primus $\cdot$ de familia / Pompeia. ${ }^{36}$ No se tiene copia en yeso en el

Maier Allende - Beltrán Fortes 2010, 256, allí ya poníamos entre corchetes la segunda numeración.

$36 \quad C I L$ II $1585\left(=C I L \mathrm{II}^{2} / 5,409\right)$. 
Museo Arqueológico Nacional, ni aparece la pieza en las fotografías de F. Valverde (véase supra, Fig. 1), por lo que seguramente ya estaba desaparecida. Solo contamos con el dibujo de A. Fernández-Guerra, que es muy simple: la representa como una caja cuadrangular, sin patas, y que no conservaba la tapadera (Fig. 6, arriba). ${ }^{37}$ P. Mérimée apuntó que el cognomen quizás habría que leerlo como Icositanus, vinculándolo a una ciudad desconocida de la Hispania meridional, ${ }^{38}$ aunque R. Thouvenot la identificaba como la Icosium mauritana. ${ }^{39}$ Sin embargo, el nombre Icstnis es de origen turdetano. ${ }^{40}$

En la urna ${ }^{\circ} 2$ se ha grabado Fabia $\cdot M($ arci $) \cdot f($ ilia $) \cdot$ Aninna / M(arci) $\cdot$ Pompei - Q(uintii) $f\left(\right.$ ilii) (scil. uxor). ${ }^{41}$ Tampoco hay copia en yeso de esta urna, que tendría patas en la caja y tapadera curva con frente redondeado y resalte posterior rectangular, según el dibujo (Fig. 6, centro y abajo). ${ }^{42}$ Las letras de la lín. 2, donde se sitúa el nombre del marido, son de menor tamaño y peor ejecución, según el calco de E. Hübner, que vio el original, ${ }^{43}$ frente al dibujo de A. Fernández-Guerra, más regular; no se ha grabado el cognomen del marido, a pesar de que había espacio disponible. El cognomen de la esposa, Aninna, es de origen indígena, turdetano. ${ }^{44}$

Fig. 6. Dibujos de las urnas de M. Pompeius Icstnis (arriba) y de Fabia Aninna (centro y abajo), realizadas por A. Fernández-Guerra en 1834. Colección familia Miranda Valdés (según Maier - Beltrán 2010, 256)

\footnotetext{
Vid. Rodríguez Oliva 2010, 152, nº 1, fig. 9.

Mérimée 1844, 177 y 180.

Thouvenot 1940, 208.

Albertos Firmat 1966, 123, 276 y 284; Abascal Palazón 1994, 389.

CIL II 1586 (=CIL II $2 / 5,410)$.

Rodríguez Oliva 2010, 152-153, nº 2, figs.10-11.

Exempla, 43a.

Albertos Firmat 1966, 26 y 276; Abascal Palazón 1994, 276.
} 
La urna $\mathrm{n}^{\mathrm{o}} 3$ presenta la inscripción $Q($ uinti) $\cdot$ Pompeì $\cdot Q($ uinti) $\cdot f($ ilii) $\cdot$ Sabinì, en genitivo, por tanto. ${ }^{45}$ Para E. Hübner la paleografía era claramente de época de Augusto, con letras cuadradas bien ejecutadas y buena ordinatio. Corresponde a una caja en la que se han individualizado las patas, mientras que la tapadera tiene forma a doble vertiente, moldurada, con laterales elevados; se conserva la copia en yeso, de $19 \times 39$ x 19,5 cm (MAN no inv. 16786) ${ }^{46}$ En este caso es completa la latinización de los tria nomina, con un cognomen de origen itálico, bastante frecuente en la onomástica hispana. ${ }^{47}$

A su vez, la urna $\mathrm{n}^{\mathrm{o}} 4$ presenta la inscripción Pompeiae $\cdot Q($ uinti) $\cdot f($ iliae $) /$ Nannae, asimismo en genitivo. ${ }^{48}$ También tiene similar disposición de las patas en la caja, como la anterior, pero con la tapadera curvada, sin resaltes; se conserva la copia en yeso, pero sin la tapadera, con las dimensiones de 17,5 x 32 × $24 \mathrm{~cm}\left(\mathrm{MAN} \mathrm{n}^{\circ}\right.$ inv. 16780). ${ }^{49}$ En este caso E. Hübner fechó las letras en época de Augusto. El cognomen es de origen indígena, derivado del balbuceo infantil..$^{50}$

En la urna ${ }^{0} 5$ se lee Sisean $\cdot$ Bahan/nonis $\cdot f($ ilius $) .{ }^{51}$ El cuerpo de la urna no tiene patas y la tapadera es lisa de sección curva; sí existe copia en yeso completa, de 22 x 32,5 x 21,5 cm (MAN n ${ }^{\circ}$ inv. 16781) (Fig. 7). ${ }^{52}$ Tradicionalmente se había leído el nombre como Siseanbahan, Nonis $f($ ili- $),{ }^{53}$ pero en la copia en yeso se advierte un punto tras Sisean, como también se recoge en $C I L \mathrm{II}^{2} / 5,418$. El nombre Sisean es indígena, turdetano, con la terminación -ean que lo relaciona con la del nombre Agalean $;{ }^{54}$ este se documenta en la misma epigrafía de Torreparedones, ya que aparece grabado en un exvoto de pierna en el contexto del santuario, extraurbano, anexo a la muralla urbana meridional, y dedicado seguramente a Dea Caelestis-Iuno Lucina o a una divinidad local asimilada a ellas ${ }^{55}$ Para el nombre patronímico Hanno(n) se había destacado su raigambre semita, ${ }^{56}$ derivado del fenicio, "con significado de 'favor, gracia, piedad' (+ divinidad)", ${ }^{57}$ por lo que en la forma Bahanno(n) se puede ver la asociación con el nombre del dios Baal. Precisamente en Gades se documenta la forma Banno, con paralelos norteafricanos, como Banno o Bannonis, y en Sicilia, bajo grafías más cercanas, como Bahanno y Bahano. ${ }^{58}$ La división del nombre del padre en el frente de la urna es consecuencia de una mala ordinatio, por lo que el final del nombre se ha grabado a la derecha de la lín. 2 para dar a entender que claramente era continuación del nombre iniciado en la línea anterior.

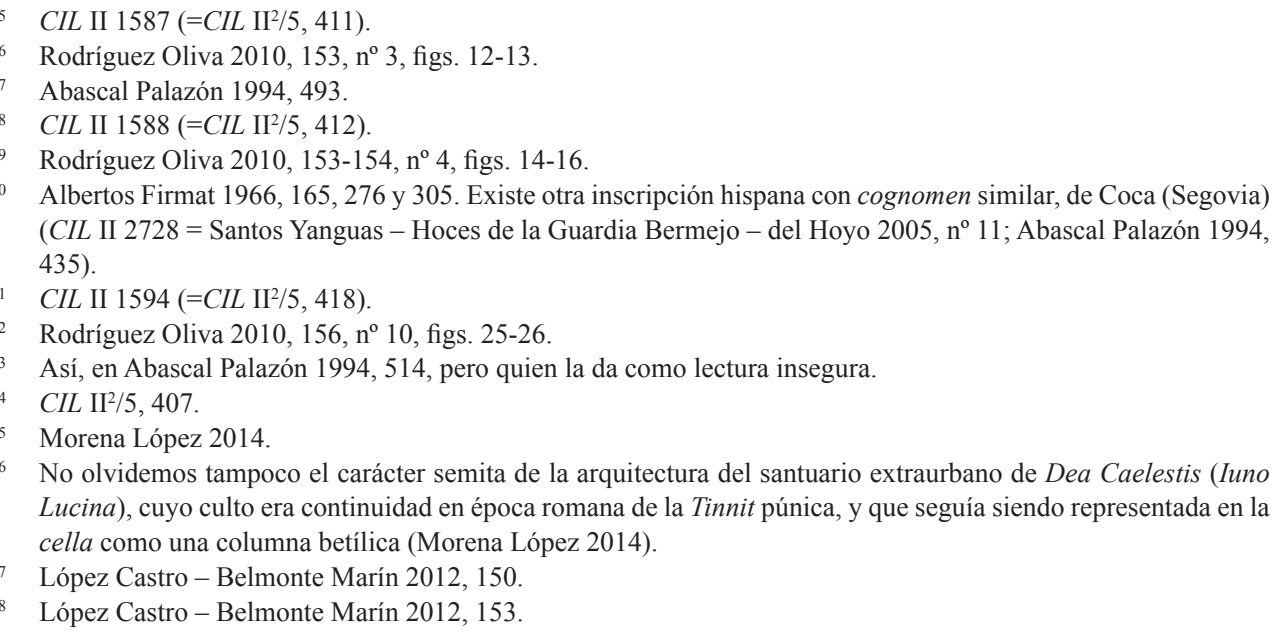




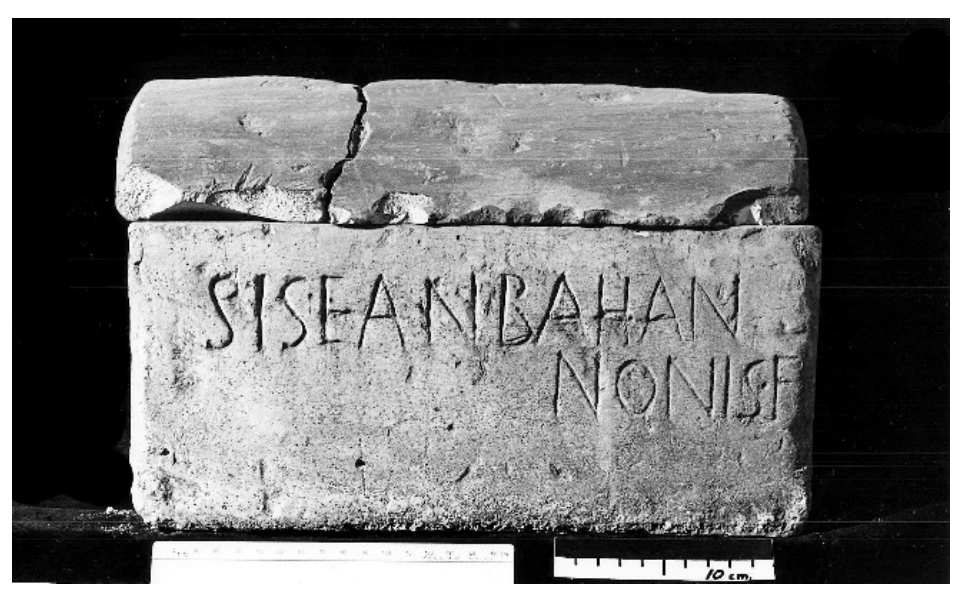

Fig. 7. Copia en yeso de la urna de Sisean. Museo Arqueológico Nacional, Madrid (Archivo fotográfico del Centro CIL II; Gerardo Kurtz)

La urna $n^{\circ} 6$ dispone el epígrafe $Q$ (uintus) $\cdot$ Pompeius $\cdot Q$ (uinti) $\cdot f($ ilius $) /$ Velaunis. ${ }^{59}$ Según se advierte en la copia en yeso, completa, la caja tiene patas, poco diferenciadas, y la tapadera es simple, curvada; las dimensiones son 21 x 32 x $18 \mathrm{~cm}$ (MAN n ${ }^{\circ}$ inv. 16785) (Fig. 8). A. Fernández-Guerra indica que estaba rota y había sido arreglada con lañas de plomo. ${ }^{60}$ Es de destacar que el cognomen Velaunis, que ocupa la lín. 2, es de mayor tamaño que el resto del nombre de la lín. 1, seguramente para resaltar ese elemento onomástico que lo vinculaba al antepasado familiar más antiguo documentado en la tumba, según pensamos. El cognomen Velaunis es también de origen indígena, con el prefijo Vel- propio del mundo turdetano. ${ }^{61}$

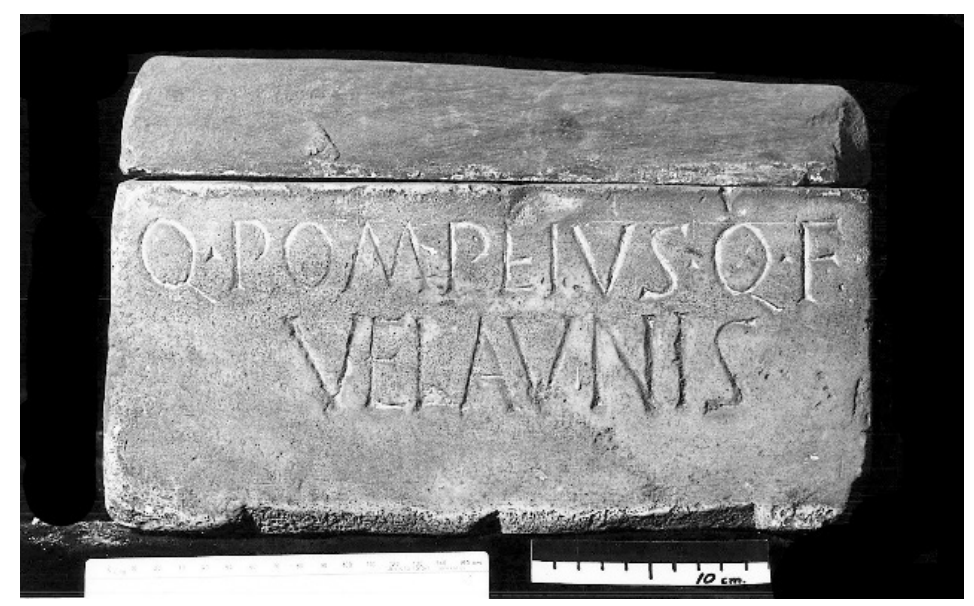

Fig. 8. Copia en yeso de la urna de Q. Pompeius Velaunis. Museo Arqueológico Nacional (Archivo fotográfico del Centro CIL II; Gerardo Kurtz)

CIL II 1589 (=CIL II $\left.{ }^{2} / 5,413\right)$.

Rodríguez Oliva 2010, 154, $\mathrm{n}^{\circ}$ 5, figs. 17-18.

Albertos Firmat 1966, 245, 262, 267 y 276; Abascal Palazón 1994, 540. 
En la urna $\mathrm{n}^{\mathrm{o}} 7$ se lee Ildrons / Velaunis $\cdot f($ ilius $) .{ }^{62}$ En este caso las patas están delimitadas por cortes rectos y la tapadera, curva, es lisa, según el dibujo, ya que no se conserva copia en yeso. ${ }^{63}$ En este caso el patronímico (lín. 2) está elaborado en letras de menor tamaño. El nombre Ildrons es de origen indígena. ${ }^{64}$

En la urna ${ }^{0} 8$ se grabó el nombre de Iunia $\cdot L\left(\right.$ ucii) $\cdot f($ ilia $) /$ Insghana ${ }^{65}$ La urna presenta patas y la parte inferior entre ellas con perfil convexo contrapuesto, con una tapadera lisa de sección curva; tampoco hay copia en yeso ${ }^{66}$ E. Hübner data estas letras, bien ejecutadas y con cuidada ordinatio, en época de Augusto. El cognomen Insghana es otro nombre indígena, que ha sido relacionado en su terminación con el nombre Velgana, documentado en esta serie y que veremos a continuación. ${ }^{67}$

En la urna $n^{\circ} 9$ se ha inscrito Igalghis $\cdot$ Ildronis $\cdot f($ ilius $) .{ }^{68}$ De esta sí tenemos la copia completa en yeso, con patas en la caja, con cortes rectos, y una tapadera plana lisa; las dimensiones son 25,5 x $39 \times 21 \mathrm{~cm}$ (MAN no inv. 16783) (Fig. 9). ${ }^{69}$ Todo el epígrafe ocupa una sola línea, bien desarrollado, frente al dibujo de A. FernándezGuerra, que comprime el nombre del padre. El trazo más grueso de la última I del nombre del padre que se advierte en la copia en yeso parece indicar que existe un nexo NI; pero la I no es longa y en $C I L \mathrm{II}^{2} / 5,415$ se acepta la forma Ildrons. Igalghis, como Ildrons, es nombre turdetano. ${ }^{70}$

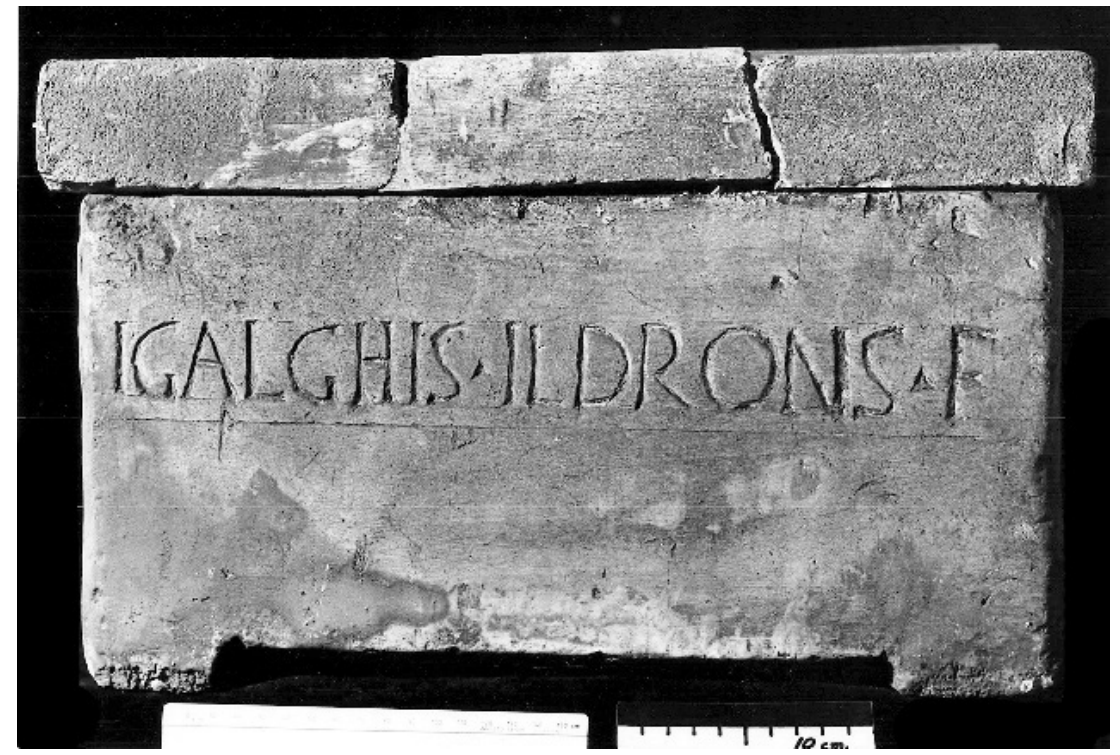

Fig. 9. Copia en yeso de la urna de Igalghis. Museo Arqueológico Nacional, Madrid (Archivo fotográfico del Centro CIL II; Gerardo Kurtz)

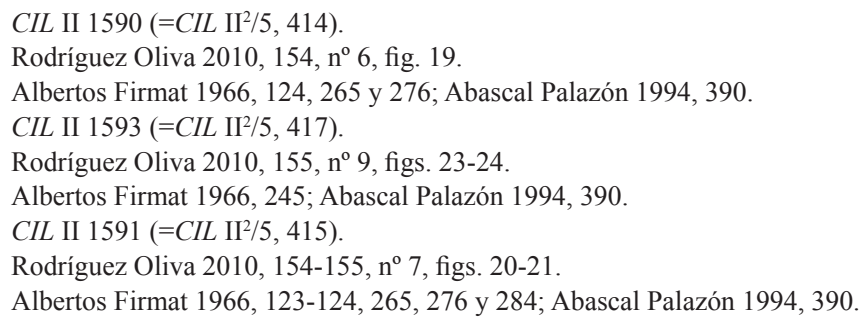


En la urna $\mathrm{n}^{\mathrm{o}} 10$ aparece inscrito solo el nombre indígena Velgana,${ }^{71}$ con nexo NA en las dos últimas letras; ello frente a la lectura Velgaan, si seguimos la afinidad de la terminación con Insghana. ${ }^{72} \mathrm{Se}$ ha indicado asimismo la lectura Velgan, con dudas, ${ }^{73}$ pero se advierte claramente el nexo NA en la copia en yeso (Fig. 10), así como en el dibujo (Fig. 11, arriba). Vemos que las patas de la caja sí están presentes, pero poco delimitadas; la tapadera es lisa de sección curva; las dimensiones son 22 x 25 x $23 \mathrm{~cm}$ (MAN no inv. 16784). ${ }^{74} \mathrm{~A}$. Fernández-Guerra apunta que tenía arreglos antiguos con lañas plúmbeas, aunque no se representan en su dibujo. El nombre no se acompaña de patronímico, y tiene una mala ordinatio, ya que empieza muy a la derecha y le falta espacio al final, lo que justificaría el nexo.

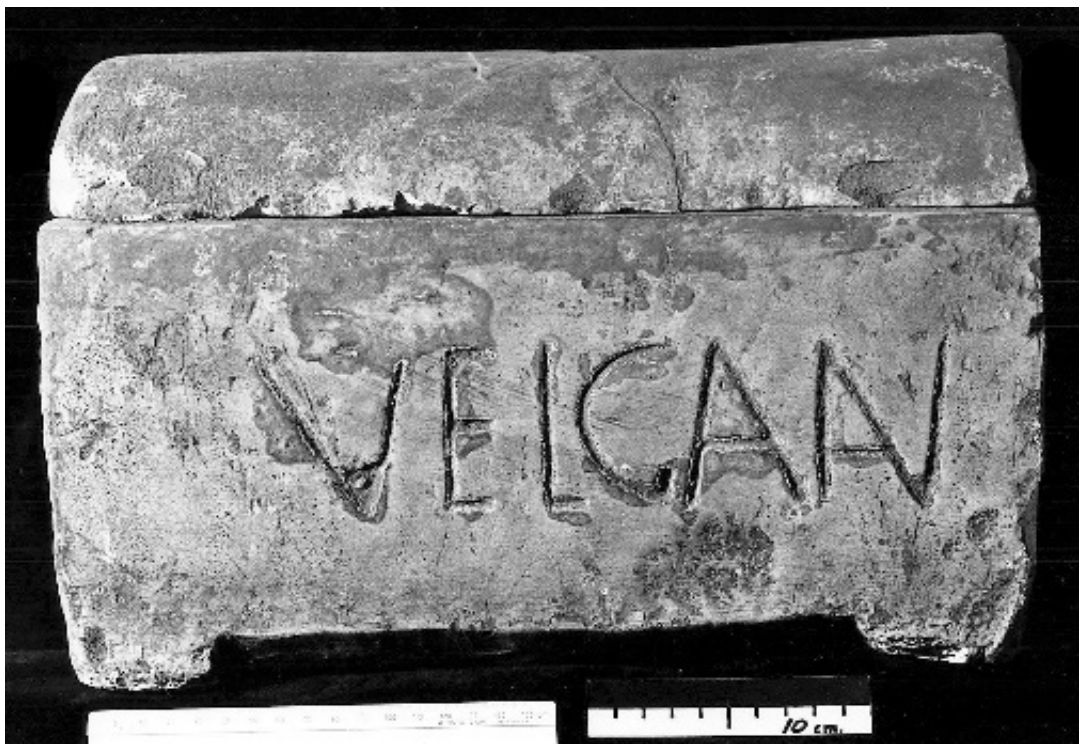

Fig. 10. Copia en yeso de la urna de Velgana. Museo Arqueológico Nacional, Madrid (Archivo fotográfico del Centro CIL II; Gerardo Kurtz)

En la urna ${ }^{\circ} 11$ se ha grabado simplemente Gracchi, en genitivo y con I longa. ${ }^{75}$ No se conserva copia en yeso, por lo que solo tenemos en este caso el dibujo de A. Fernández-Guerra del cuerpo de la urna, con patas y cortes curvos entre ellas, similares a las urnas de Iunia Insghana, Pompeia Nanna y Q. Pompeius Velaunis. ${ }^{76}$ Se constata una mala colocación del nombre en el campo disponible, pero en este caso no se conserva la copia del original, por lo que no sabemos si se trata de un defecto del dibujo; sin embargo, A. Fernández-Guerra añade que era la peor ejecutada, tanto en la elaboración del contenedor cuanto de la inscripción. El nombre, latino, no se acompaña del patronímico, pero a pesar de ello debe de corresponder a un peregrinus con un nombre latinizado, descartándose que pueda ser un esclavo, por el

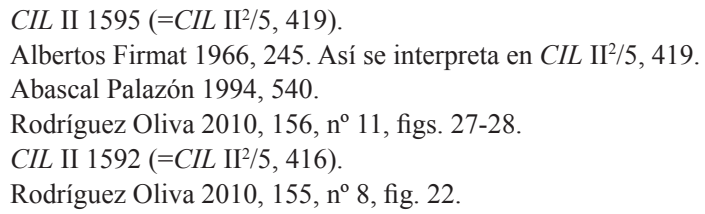


carácter familiar de la tumba. Un Gracchus se documenta en una inscripción de la cercana ciudad romana de Ipsca, localizada en el cortijo de Iscar, en el mismo término municipal de Baena. ${ }^{77}$

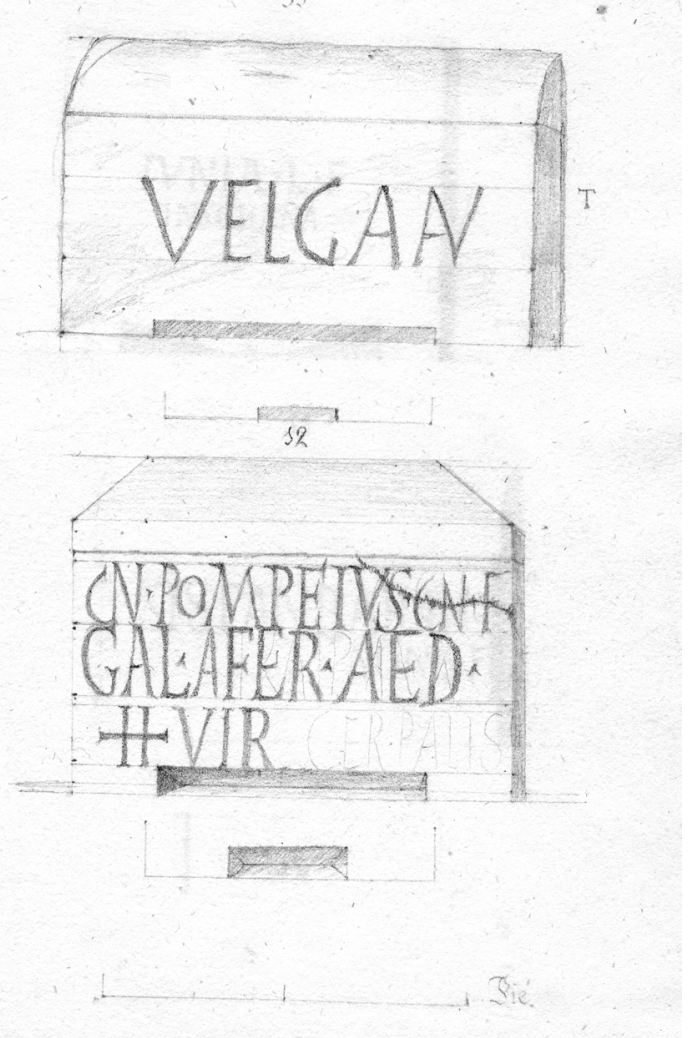

Fig. 11. Dibujos de los frentes de las urnas de Velgana (arriba) y de Cn. Pompeius Afer (abajo), realizados por A. Fernández-Guerra, en 1834. Colección familia Miranda Valdés (según Maier - Beltrán 2010, 257)

Finalmente, en la urna ${ }^{\circ} 12$ se ha grabado $C n($ aeus $) \cdot$ Pompeius $\cdot C n(a e i) \cdot f(i l i u s)$ / Gal(eria) $\cdot$ Afer $\cdot$ aed(ilis) $\cdot /$ II vir. ${ }^{78}$ La caja rectangular tiene las patas delimitadas mediante cortes rectos y la tapadera es lisa y plana; las dimensiones son 25 x 33,5 x $23 \mathrm{~cm}$ (MAN n ${ }^{\mathrm{o}}$ inv. 16800) (Fig. 12).$^{79} \mathrm{La}$ inscripción está hecha en letras capitales cuadradas, pero de diferente tamaño-siendo de dimensiones menores las letras de la lín. 1-y ejecución, con letras de módulo más alargado en algunos casos. El cognomen Afer es latino, de origen étnico, y está documentado en Hispania, aunque no es muy abundante.$^{80}$ Interesante es el hecho, indicado por A. Fernández-Guerra, de que había

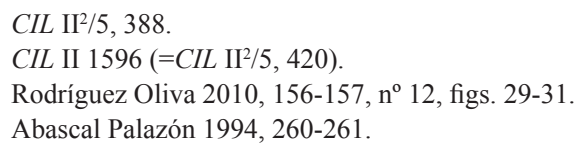


restos de una inscripción infrapuesta a la anterior, de la que se podría leer en las dos últimas líneas: ${ }^{81}$ FER AED [- - - ]VR / II+I+ Cerealis (Fig. 11, abajo). Se ha interpretado como: AED [II]VIR / IIV[IR] III CEREALIS. ${ }^{82}$ Según explicaba el mismo A. Fernández-Guerra: "El picapedrero que hizo el sepulcro trazó con el buril la inscripción y luego la fue corrigiendo: de manera que en donde trazó la r puso la e, y donde la a puso la r y luego la a AFER AED y le parecio demás cerialis (si lo dice así). La única letra borrada en mi concepto es la D por el hoyo". "No obstante, también indica este mismo autor que esa segunda inscripción era un titulus pictus. Por la relación con la inscripción finalmente grabada, el titulus pictus debió de ser una versión anterior que no llegó a grabarse exactamente, como afirma Armin U. Stylow: “. . tituli minio scripti, cum titulus alter arcae incideretur, omissi sunt”. ${ }^{44}$

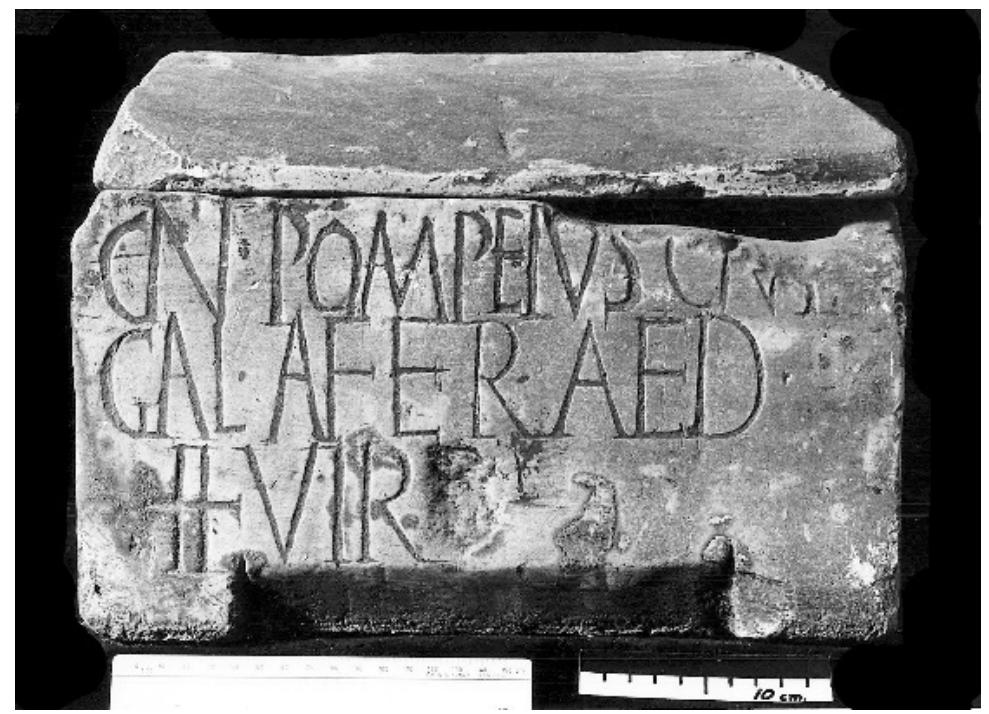

Fig. 12. Copia en yeso de la urna de Cn. Pompeius Afer. Museo Arqueológico Nacional, Madrid (Archivo fotográfico del Centro CIL II; Gerardo Kurtz)

\section{Propuestas de relaciones familiares: P. Mérimée, E. Hübner, M. Rodríguez de Berlanga}

Diversos autores han hecho propuestas sobre las relaciones familiares a las que el análisis de los nombres podía llevar. Fue precisamente P. Mérimée quien dio el primer paso, en línea con el interés de su estudio. Así, considera que Ildro o Ildron, hijo de Velaunis, es el "chef de la famille", con la hipótesis de que a ese Velaunis correspondería la urna con la inscripción Velgan-según su lectura-, por "la difficulté de transcrire en lettres romaines des noms barbares"; 85 pero ello no nos parece

\footnotetext{
Maier Allende - Beltrán Fortes 2010, 257.

Galsterer 1971, 59; CIL II $2 / 5,420$.

Maier Allende - Beltrán Fortes 2010, 276.

Apud CIL $\mathrm{II}^{2} / 5,420$.

Mérimée 1844, 181
} 
pertinente, pues el nombre Velaunis aparece correctamente inscrito en las otras urnas en dos ocasiones. Por el contrario, sí es evidente la relación filial de Ildrons con Velaunis. Según el estudioso francés esta familia adoptó el nombre romano de Pompeius de un individuo con praenomen Quintus padre de Q. Pompeius Velaunis -que recuperaba el nombre ancestral en su cognomen- y de su hermana Pompeia Nanna. Siguiendo con su propuesta de stemma, de Q. Pompeius Velaunis -o incluso de su padre $Q$. Pompeius, pero cuyos restos no estarían en la tumba-serían hijos: $M$. Pompeius Icstnis, casado con Fabia Aninna, y Q. Pompeius Sabinus; mientras que del resto "il nous paraît imposible de les rattacher avec certitude aux précédents". ${ }^{86}$ Este resulta un intento loable de reconstrucción parcial del cuadro familiar para aquellos momentos.

El siguiente paso, más consistente, lo da E. Hübner en 1861, cuando - de manera novedosa- hace referencia a la colocación de algunas urnas en el mausoleo, pero siguiendo erróneamente la ordenación de los dibujos de A. Fernández-Guerra -con el que tuvo contactos en el marco de la elaboración del CIL II- ${ }^{87}$ e incluso en ese caso con alguna imprecisión o ausencia. Así, dice: ${ }^{88}$

A destra dell'ingresso stava l'urna del capo della familia (Henzen 7042), $M$. Pompeius Q.f. Icstnis (...) A sinistra stava l'urna di un altro magistrato della stessa familia: C. Pompeius C. f. Gal. Afer (...) Accanto all'urna del primo Pompeo stava quella della sua moglie Fabia M. f. Aninna; seguono quelle di due fratelli di lui: Q. Pompeius Q. f. Sabinus e Velaunis. ${ }^{89}$ Il centro della parete, dirimpetto all'ingresso, ocupa un peregrino, come fanno fede i suoi nomi Igalghis Ildrons f(ilius) (...) Accanto a Igalghis riposano le ceneri del suo padre Ildrons Velaunis $f$., e dall'altro lato quelle di uno chiamato semplicemente Gracchus, forse un servitore della casa, come il Velgaan (cosi) riposante a sinistra de Cn. Pompeo. Le due urne che restano, sono quelle d'una Iunia L. f. Insghana e d'un Siseanba Hannonis $f$. (così sembra esser da dividere, non Sisean Bahannonis; un punto in mezzo non existe) ${ }^{90}$

También la numeración de las inscripciones de las urnas sigue ese orden en $C I L$ II. ${ }^{91}$ E. Hübner coincide con P. Merimée en pensar que Fabia Aninna era la mujer de M. Pompeius Icstnis, al que considera el personaje principal de la familia, siendo sus hermanos los Pompeii con los cognomina Sabinus y Velaunis.

Finalmente, el estudioso M. Rodríguez de Berlanga, en 1881, cuando estudia los bronces jurídicos romanos de Lascuta, Bonanza y Aljustrel, también indaga en el stemma familiar de estos Pompeii, ${ }^{92}$ de una manera algo diferente que los dos anteriores autores. Así, considera -como ellos- que Fabia Aninna y M. Pompeius Icstnis eran matrimonio, pero que hermanos de este segundo serían Q. Pompeius Sabinus y Pompeia Nanna, lo que nos parece acertado asimismo por la colocación de

\footnotetext{
Mérimée 1844, 181.

Stylow - Gimeno Pascual 2004, 334-336; Miranda Valdés 2005, 96-98.

Hübner 1861, 232.

Se olvida Hübner de la colocación de la urna de Pompeia Q. f. Nanna a continuación de la de Q. Pompeius Sabinus.

90 Por el contrario, sí existe el punto, según se aprecia en el calco en yeso; así se recoge también en CIL II²/5, 418 . CIL II 1585-1596; y se ha mantenido en $C I L \mathrm{II}^{2} / 5$, 409-420.

92 Rodríguez de Berlanga 1881, 255-259; reproducido también en Maier Allende - Beltrán Fortes 2010, $283-285$.
} 
las urnas en la tumba, mientras que -menos cierto a nuestro juicio- el cognominado como Velaunis sería sobrino de los primeros, hijo de Sabinus.

Por otro lado, según se refleja en el stemma familiar que intercala en su obra (Fig. 13), identifica a este $Q$. Pompeius Velaunis con el padre de Ildrons, que aparece citado como Velaunis en su urna, por lo que Igalghis sería a la vez hijo y nieto de ambos, respectivamente. Según se ha dicho ya, no nos parece plausible, siendo más factible que ese Velaunis citado como padre de Ildrons sea un antepasado y que Q. Pompeius Velaunis recuperó en su cognomen el nombre indígena familiar algunas generaciones después. Finaliza M. Rodríguez de Berlanga con la lógica consideración de que era más difícil establecer el grado de relaciones familiares con el resto de personajes citados en las urnas.

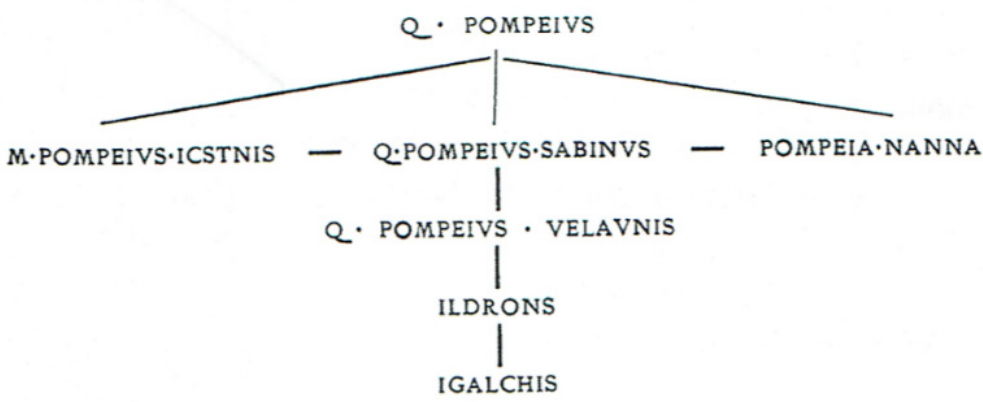

Fig. 13. Stemma elaborado por M. Rodríguez de Berlanga en 1881 (Maier - Beltrán 2010, 284)

\section{Propuesta de relaciones familiares a la luz de los datos aportados por A. Fernández-Guerra}

Nos parece evidente que la colocación de las urnas en el interior de la cámara, como ya indicó E. Hübner, debe aportar base a una nueva hipótesis que complete de manera más ajustada las ya expuestas. Partimos, pues, de la ordenación establecida por A. Fernández-Guerra (Fig. 4): la urna de M. Pompeius Icstnis ocupa la esquina a la derecha de la entrada, seguida -ya en el lado meridional- de las de Fabia Aninna, $Q$. Pompeius Sabinus y Pompeia Nanna. En el lado oriental, el más importante, de frente a la entrada de la cámara, se situaba en el centro la urna de Ildrons, hijo de Velaunis, en el lugar principal, ya que se trataría del personaje más antiguo de entre los allí enterrados; flanqueando la urna de Ildrons estaría -a la derecha, de frente desde la puerta de entrada- la de Q. Pompeius Velaunis, así como - a la izquierda- la de Iunia Insghana; finalmente, en el extremo derecho se situaría la de Sisean y en el extremo izquierdo la de Igalghis, hijo de Ildrons. En el lado septentrional no sabemos qué urna u objeto se situaba en el lugar central, marcado con la letra A, mientras que a ambos lados de ese lugar estarían situadas - de frente al espectador- la urna de Velgana, a la derecha, y la urna de Gracchus, a la izquierda. Cerrando ese lado norte, se situaría el contenedor de las cenizas de Cn. Pompeius Afer, en la esquina noroeste.

Antes de pasar a la interpretación de las relaciones familiares que proponemos, hemos de hacer una serie de consideraciones. En primer lugar, que nos encontramos 
ante un mausoleo familiar, el de la familia Pompeia, según se dice, y que por tanto todos los individuos allí enterrados pertenecen a ella o son antecesores al momento de su conformación. Ello ha sido aceptado desde el primer estudio de P. Mérimée, quien indicaba que los individuos que no portaban el nomen Pompeius eran asimismo miembros familiares; para él era precisamente Ildrons el "chef de la famille", en lo que estamos de acuerdo, pero solo en cuanto el individuo más antiguo de la familia, por lo que ocupaba el lugar preeminente que hemos visto.

En segundo lugar, creemos que no es adecuado, por el contrario, pensar que a Ildrons se pueda deber la construcción del monumentum. Puede mantenerse como hipótesis que la tumba fue construida por uno de sus descendientes, quizás $Q$. Pompeius Velaunis o, más seguramente -se dirá luego-, M. Pompeius Icstnis, "capo della familia", según apuntó de manera adecuada E. Hübner. ${ }^{93}$ La presencia de las cenizas de antepasados de varias generaciones familiares debió de constituir una especie de "refundación" de la línea familiar en el ambiente del mausoleo situado en la necrópolis septentrional de la ciudad romana ${ }^{94}$ estableciendo una jerarquía generacional de transmisión parental. Las urnas de esos antepasados debieron ser trasladadas desde otra tumba anterior a este nuevo monumentum o incluso se pudieron elaborar entonces las urnas como nuevos contenedores para recibir las cenizas de los antepasados. Si analizamos las urnas comprobamos que no presentan las mismas formas, con variantes tanto en las cajas como en las cubiertas; y lo mismo ocurre con las inscripciones, tanto en la paleografía como en la estructura onomástica. En efecto, nos encontramos con variantes en la referencia a los difuntos: ${ }^{95}$ 1) un solo nombre indígena (Velgana); 2) un solo nombre, latino (Gracchus); 3) un nombre indígena con la indicación del patronímico, asimismo indígena, pero con el término latino filius (Ildrons Velaunis f.; Igalghis Ildrons $f$.; Sisean Bahannonis $f$.); 4) tria nomina con filiación y cognomen indígena, pero sin indicación de la tribus $(Q$. Pompeius $Q$. f. Velaunis); 5) tria nomina con filiación y cognomen indígena, con indicación de la tribus (M. Pompeius Q.f. Gal. Icstnis); 6) tria nomina latinos, con filiación, pero sin indicación de la tribus (Q. Pompeius $Q$. f. Sabinus); 7) tria nomina latinos con filiación y tribus (Cn. Pompeius Cn.f. Gal. Afer); 8) duo nomina femeninos con el gentilicio romano y el segundo nombre indígena, y con indicación de la filiación (Fabia M.f. Aninna; Pompeia Q.f. Nanna; Iunia L.f. Insghana). Esa gran variedad onomástica sería exponente de un mundo social cambiante durante el siglo I a.C. en la Hispania Ulterior, acorde con los cambios políticos, ideológicos y económicosociales que se estaban produciendo. ${ }^{96}$

Podemos hacer referencia a un claro ejemplo de un acontecimiento que debió ser similar a lo ocurrido en la "tumba de los Pompeyos" y que hemos documentado en fecha reciente en la misma necrópolis septentrional de Torreparedones. Así, hemos constatado arqueológicamente un mausoleo, con una cámara sepulcral muy

\footnotetext{
Hübner 1861, 232.
}

94 Beltrán Fortes 2014a. Junto a esta necrópolis septentrional destaca asimismo la necrópolis oriental, según los testimonios arqueológicos conocidos hasta ahora; Tristell - López 2014. En esta última acaba de ser documentada una cámara sepulcral, con repisa para la colocación de urnas, que es muy similar a la que estudiamos, aunque se encuentra muy deteriorada y no se conservan las urnas. Agradezco a José Antonio Morena esta información.

95 No incluimos como variante el nombre del marido de Fabia Aninna, referido en la urna de ella solo como $M$. Pompeius Q.f., sin cognomen, pues consideramos que se trata del mismo M. Pompeius Q.f. Icstnis, del que no se repite el cognomen, ya que también estaba colocado al lado de la urna de su mujer.

96 Por ejemplo, Beltrán Fortes 2014b. 
parecida a la del mausoleo de los Pompeii, con una repisa perimetral para colocar las urnas - pero de las cuales solo se recuperó la tapadera pétrea de una de ellas, por el arrasamiento que tenía la tumba-, en cuya construcción se reemplearon elementos de otro monumentum anterior. ${ }^{97}$ Aquel más reciente lo hemos datado en época augustea, mientras que el más antiguo - de varios pisos en forma de edícula- sería de época cesariana o a lo sumo augustea temprana, y que, por alguna razón que desconocemos, fue desmontado y sirvió para la construcción del segundo. Algo parecido ocurriría en esta ocasión, y el "jefe de la familia", M. Pompeius Icstnis, que había alcanzado la máxima magistratura de la comunidad por vez primera (IIvir primus de familia Pompeia), construyó un mausoleo adecuado al nuevo prestigio adquirido, colocando en este las cenizas de sus antepasados de varias generaciones. También debemos recordar que dos de las urnas, la de Q. Pompeius Velaunis y la de Velgana, tenían lañas de plomo para arreglar desperfectos del contenedor, que quizás se hicieron en el momento de este trasvase, a no ser que se reutilizaran otros contenedores.

En tercer lugar, hay que considerar el carácter de la ciudad romana que se corresponde con el yacimiento de Torreparedones. En la historiografía local se identificaba el lugar como el municipio romano de Castrum Priscum, que es inexistente y que derivó de la errónea consideración de una inscripción dedicada a Licinia Rufina, aparecida en estas tierras del cortijo de las Vírgenes. ${ }^{98}$ Ya E. Hübner propuso situar aquí la colonia Ituci Virtus Iulia, ${ }^{99}$ citada por Plinio el Viejo, ${ }^{100}$ 1o que se ha aceptado posteriormente de manera general, ${ }^{101}$ discutiéndose si fue una deductio de época de César o de Augusto. ${ }^{102}$ Se ha planteado que sería extraña la promoción de unos Pompeii -y hemos de incluir las dos ramas familiares, de los Quinti y de los Cnaei- en una colonia cesariana, pues la deductio respondería a una represalia en una comunidad propompeyana, sobre todo, en gentes de la antigua clientela de Cneo Pompeyo el Grande, por lo que se ha considerado más adecuada su constitución en el período de Augusto; la promoción al duovirato de M. Pompeius Icstnis podría haberse producido en un momento avanzado del principado augusteo, alejado ya el recuerdo de los enfrentamientos civiles entre César y Pompeyo. ${ }^{103}$

Otra identificación más reciente de Torreparedones se establece a través de una inscripción recuperada en las excavaciones arqueológicas de las termas orientales, grabada sobre una fistula aquaria de plomo; en ella parece haber una referencia al municipium Borense, que es conocido por una sola y corta emisión de monedas de bronce, con la mención de BORA, y que tradicionalmente se ha situado en el término municipal de Martos. ${ }^{104}$ Podría pensarse incluso que, si se tratara de un municipio augusteo, se explicaría mejor la promoción de estos Pompeii en la comunidad, donde no habrían competido con una élite colonial foránea, pero tampoco es segura la interpretación del epígrafe y hemos de aguardar al estudio de los investigadores

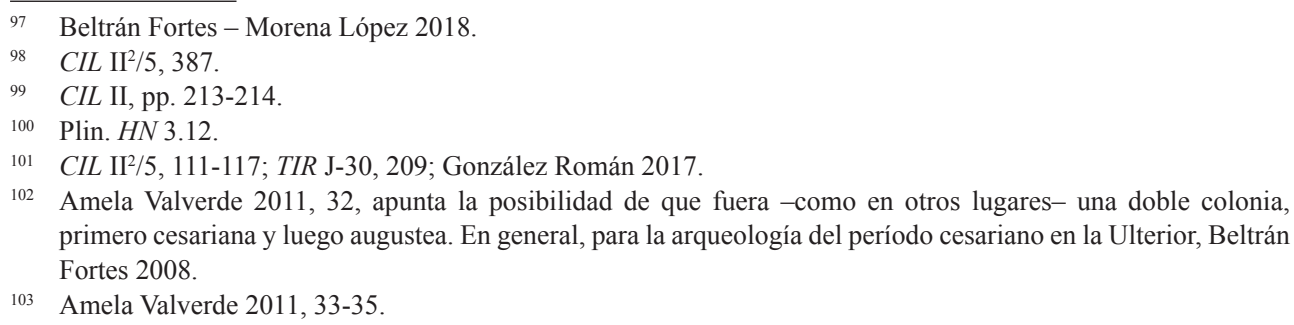

104 TIR J-30, 112. 
para su correcta valoración. ${ }^{105}$ Debemos, pues, mantener que se trata de la colonia Virtus Iulia, a lo que apuntan otros argumentos, ${ }^{106}$ deducida seguramente en época de Augusto; de ahí que sus ciudadanos -como ocurre con los dos Pompeii que lo indican en sus respectivas inscripciones sepulcrales-se integren en la tribus Galeria. Por tanto, ello establece una fecha post quem para la muerte de M. Pompeius Icstnis y de Cn. Pompeius Afer.

Teniendo en cuenta tales consideraciones, la disposición de las urnas en la tumba parece indicar las relaciones familiares a las que apunta la onomástica. ${ }^{107}$ Así, pensamos que el constructor de la tumba debió de ser M. Pompeius Icstnis, ya adscrito a la tribus Galeria, y que desempeña el duovirato por vez primera en la familia Pompeia de esa comunidad; ${ }^{108}$ es significativo que tiene un praenomen (Marcus) diverso del de su padre (Quintus), lo que indica que no era el primogénito. Junto a él se situaría la urna de su esposa, Fabia Aninna, hija de un Marcus Fabius; en la inscripción de esta solo se dice que era mujer de M. Pompeius $Q$ (uinti) f(ilius), sin incluir el cognomen, pero creemos que es plausible pensar que se refiere al anterior, pues la ausencia se puede justificar por error lapidario o, mejor, porque era evidente al estar colocada a su lado en el contexto familiar. ${ }^{109}$

Los padres del marido pudieron ser Q. Pompeius Q. f. Velaunis y Iunia L. $f$. Insghana, que están colocados relativamente juntos, flanqueando al "patriarca" Ildrons, hijo de Velaunis. Como se dijo, pensamos que las cenizas de este Velaunis no estarían en la cámara, pues no creemos que sus restos fueran los de la urna con la inscripción Velgana. Tampoco estaría la urna del padre del propio Q. Pompeius Velaunis, que sería un Q. Pompeius del que desconocemos el cognomen. Pudo ser en esa generación cuando ese Q. Pompeius, abuelo de M. Pompeius Icstnis, se incorporó a la gens Pompeia. No obstante, y teniendo en cuenta que también entra en la escena de los Pompeii de Torreparedones un Cnaeus Pompeius, podría pensarse en otra generación intermedia en la que un individuo itucitano -de praenomen Cnaeushubiera recibido la ciudadanía del propio Cnaeus Pompeius Magnus, en una fecha coincidente con la creación de clientelas pompeyanas en Hispania, como se dirá en el apartado siguiente. Ese hipotético Cnaeus Pompeius de Ituci podría haber tenido al menos dos hijos, el primogénito con el praenomen Cnaeus, del que descendería la rama familiar que llega a Cn. Pompeius Afer, y un hermano menor, Quintus - que es el que se cita en el patronímico de Q. Pompeius Velaunis-, del que arrancaría esta rama familiar que construyó la tumba. En ese supuesto, Ildrons podría ser padre no solo de Igalghis -como atestigua su urna-, sino también de ese hipotético Cnaeus Pompeius que hubiera recibido la ciudadanía de Pompeyo. Ildrons sería entonces bisabuelo de Q. Pompeius Velaunis y tatarabuelo de M. Pompeius Icstnis, tal como se recoge en el stemma hipotético (Fig. 13). El referido Velaunis sería, pues, el antecesor más antiguo, como padre de Ildrons, pero no estarían sus cenizas colocadas en la tumba;

\footnotetext{
Cit. en Beltrán Fortes - Morena López 2018, 34.

06 Por ejemplo, Ventura Villanueva 2014a; 2014 b.

107 Beltrán Fortes 2014a, 122-123.

108 En una ocasión anterior habíamos apuntado la posibilidad de considerar a M. Pompeius Velaunis como constructor de la tumba, por la posición que ocupaba, junto a su mujer, flanqueando al patriarca Ildrons (Beltrán Fortes 2017, 801), pero tras el estudio pormenorizado del stemma, realizado ahora, pensamos que es preferible la opción de su hijo M. Pompeius Icstnis, más acorde, además, con la fecha de construcción del mausoleo a fines del período augusteo.

109 Por el contrario, Amela Valverde 2011, 30, considera que es otro personaje, no enterrado en el mausoleo.
} 
su tataranieto Q. Pompeius Velaunis habría recuperado su nombre como cognomen.

Ello podría justificar la colocación de las urnas en la tumba: la del antecesor más antiguo en el centro del lado oriental y, flanqueándola, la del matrimonio padre y madre del "constructor" de la tumba. La urna de Igalghis, hijo de Ildrons y, por tanto, tío abuelo de $Q$. Pompeius Velaunis, se ha colocado en el extremo izquierdo del lado oriental, mientras que en el otro extremo aparece la urna de Sisean, Bahannonis f:; no podemos saber la relación exacta que le une a los anteriores, pero debió de ser importante, por la posición que ocupa su urna en la tumba.

En relación de nuevo a la generación del posible constructor, M. Pompeius Icstnis, nos parece que las otras dos urnas colocadas en el lado meridional podrían ser las de sus hermanos, como ya indicara M. Rodríguez de Berlanga (Fig. 12), dado que las tres se colocan juntas en ese lado de la tumba. Q. Pompeius Sabinus, que indica que es hijo de Quintus (Pompeius Velaunis), sería el primogénito, aunque la preeminencia familiar recayó en su hermano, seguramente por una muerte temprana -sin descendencia- que le impidió desarrollar una carrera política similar a la que sí tuvo M. Pompeius Icstnis. Asimismo, Pompeia Nanna indica que es hija de un Quintus, que podría ser el propio Q. Pompeius Velaunis, y debió morir sin casarse, ya que está enterrada en la tumba familiar paterna. También podría pensarse que esta Pompeia Nanna pudiera ser hija de $Q$. Pompeius Sabinus, pero nos parece menos probable, pues en ese caso no estaría la urna de la madre de la joven.

Quedan fuera de este stemma los individuos de las urnas colocadas en el lado norte; en primer lugar, Velgana y Gracchus. Se dijo de este último que fuera un esclavo familiar, ${ }^{110}$ por el nombre, latinizado, y la ausencia de filiación, pero realmente pensamos que debió ser un peregrinus, por el carácter familiar de la tumba, aunque desconocemos la vinculación con Ildrons e Igalghis o los posteriores. En ambos casos coincide el carácter de las dos inscripciones, indicando solo el nombre-Velgana y Gracchus, este en genitivo-, sin filiación y escrito con grandes letras capitales.

Por último, Cn. Pompeius Afer, del que se dice que ha sido aedilis y IIvir y que está adscrito lógicamente a la tribus Galeria, se aleja de la rama de los Quinti Pompeii itucitanos, ya que asimismo es hijo de un Cnaeus. Podríamos considerar que derivara de aquel hipotético Cnaeus Pompeius que recibió inicialmente la ciudadanía algunas generaciones antes. Parece, sin duda, la urna epigráfica de fecha más reciente; su presencia en este lugar, próximo a la entrada, quizás deba interpretarse como testimonio del final de la rama familiar que había agrupado el IIvir M. Pompeius Icstnis, sobre todo si se advierte que no hay ningún otro miembro familiar que indique que es hijo de un Marcus, por lo que M. Pompeius Icstnis no debió tener descendencia. Cnaeus Pompeius Afer, un familiar, un primo lejano perteneciente a la rama de los Cnaei Pompeii de la misma ciudad, se convertiría en heredero y se enterró en el mausoleo de la familia. Por ello no creemos que su muerte y, consecuentemente, la elaboración de la urna con su epígrafe, estuvieran muy alejados en el tiempo de la de su pariente M. Pompeius Icstnis.

110 Hübner 1861, 232. 


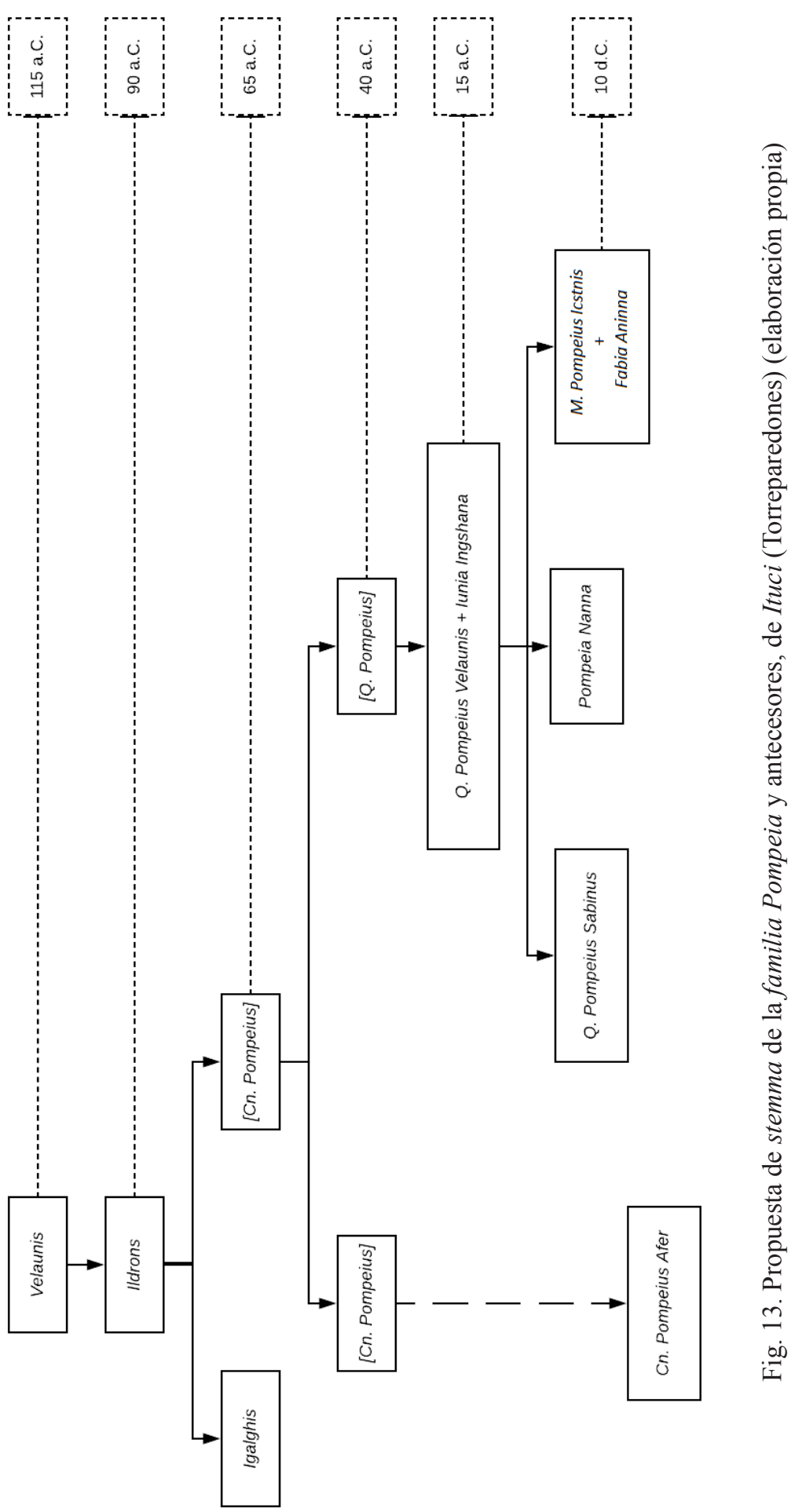




\section{La datación de las urnas}

Sobre las fechas de estas inscripciones P. Mérimée consideró que serían de una o dos generaciones después del enfrentamiento entre Pompeyo y César, o sea, en la segunda mitad del s. I a.C. Por el contrario, en un primer momento, E. Hübner consideró que la adscripción a la gens Pompeia se habría producido como fruto del desempeño de una magistratura en un municipio de derecho latino, a raíz de la concesión de Vespasiano, y en esa línea consideraba que "i caratteri [de las inscripciones] corrispondono all'epoca di Vespasiano" ${ }^{111}$ pero ya corrigió ese dato en $C I L$ II, destacando que las inscripciones de las tres urnas que analizó personalmente en Baena -las de Fabia Aninna, Iunia Insghana y Pompeia Nanna- eran de época augustea: "Litterae sunt elegantissimae aevi Augusti", ${ }^{112}$ y también en ese momento dató la construcción de la tumba, como así se ha seguido haciendo. En efecto, ya nos hemos ocupado en otra ocasión de manera pormenorizada del análisis del tipo arquitectónico y de los elementos de los ajuares de la tumba con la conclusión de que fue erigida a finales del principado de Augusto, ya en los primeros años del siglo I a.C. ${ }^{113}$ Ello lo corroboraría el hecho de que los únicos personajes que indican que pertenecen a una tribus, la Galeria, son M. Pompeius Icstnis y Cn. Pompeius Afer, ambos duoviros. Otra cosa sería el período de uso de la tumba, pues al menos la urna de vidrio con su protección plúmbea parece apuntar a un momento algo más avanzado, pero no mucho después. ${ }^{114}$

Luis Amela, especialista en las clientelas pompeyanas de Hispania, identifica a estos Pompeii de Torreparedones como "un grupo aristocrático de origen autóctono", que recibiría la ciudadanía romana "por parte de Cn. Pompeyo Magno (cos. I 70 a.C.), o de los hijos de éste, Cneo Pompeyo hijo o Sexto Pompeyo". ${ }^{115}$ Es cierto que no se puede generalizar en el caso de las clientelae provinciales tardorrepublicanas, asignando por la simple coincidencia del nombre a gentes derivadas de la política clientelar de un gobernador o imperator concreto, ${ }^{116}$ porque, por un lado, en ocasiones la elección del nombre podía ser discrecional ${ }^{117} \mathrm{y}$, por otro lado, la concesión de la ciudadanía era individual y, en todo caso, familiar, por transmisión hereditaria, ${ }^{118}$ como ocurre en este caso. Precisamente Francisco Pina afirma que "Pompey's case is the paradigm of someone who managed to create an image of an almost universal patronus that went down in history", ${ }^{119}$ aunque reconoce el valor del conjunto de Torreparedones, "members of the same family, could hypothetical be linked to Pompey's sons and their last stand against Caesar in 46-45" ${ }^{120}$ Como ya hemos dicho, pensamos que la concesión de la ciudadanía estaría en este caso vinculada a Pompeyo el Grande y no a sus hijos. En efecto, si repasamos nuestro

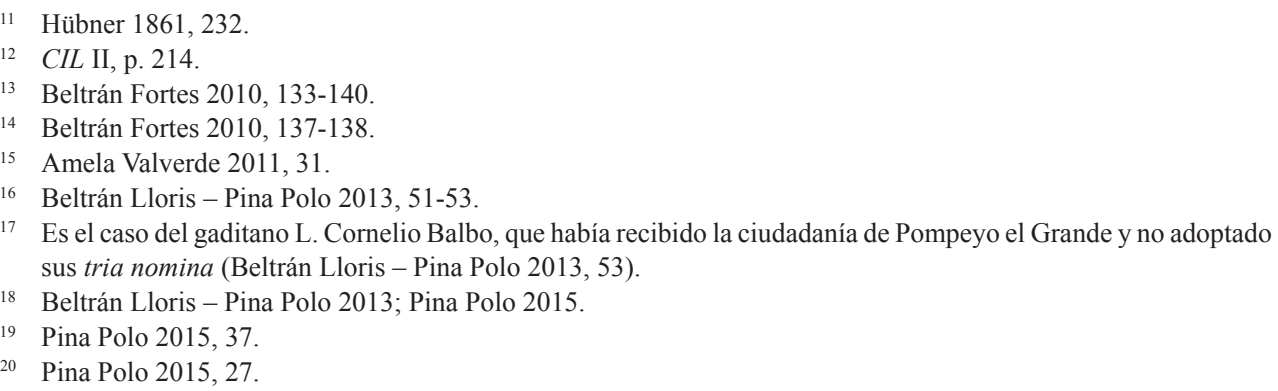


stemma propuesto (Fig. 12), se observa que desde Velaunis, en la cúspide de la pirámide familiar, hasta $M$. Pompeius Icstnis se habrían sucedido seis generaciones; si multiplicamos cada generación por un término medio de 25 años -aunque quizás debería ser menor en función de la edad media de casamiento- y pensamos que la tumba pudo construirse hacia el cambio de Era o, mejor, en los primeros años del siglo I d.C., una vez que M. Pompeius Icstnis desempeñó el duovirato en la nueva colonia y murió, llegaríamos a una fecha de aproximadamente el 115 a.C. para la muerte de Velaunis.

En ese cómputo ideal, tres generaciones antes, el Cnaeus Pompeius que recibiera la ciudadanía de Pompeyo el Grande pudo morir hacia el 65 a.C. No debemos olvidar que fue a fines de la década de los 70 a.C. cuando Pompeyo conformó sus principales clientelas en Hispania, ${ }^{121}$ en el marco de las guerras sertorianas, en las que intervino activamente. Sertorio fue asesinado en el 73 a.C. y en los primeros meses del 71 a.C. Pompeyo volvió a Roma, por lo que es factible en el marco de su actuación en el territorio hispano la concesión de la ciudadanía a ese hipotético Cn. Pompeius itucitano durante aquel decenio.

Desconocemos los avatares de aquellos Pompeii de Ituci a lo largo del convulso siglo I a.C., y ello podría explicar el que no hubieran tenido sepultura en la tumba ni aquel Cn. Pompeius, ni su hijo Q. Pompeius, el padre de Q. Pompeius Velaunis. Sus vidas ocuparían los dos cuartos centrales del siglo I a.C., plenos de acontecimientos sangrientos, desde la campaña cesariana del año 49 a.C. hasta la batalla de Munda en el 45 a.C.; es por ello por lo que quizás no llegaron a estar sus restos resituados en la nueva "tumba de los Pompeyos" en el principado augusteo. A pesar de las vicisitudes que desconocemos, la familia Pompeia de Ituci no desapareció de la nómina ciudadana, incluso portando el nombre del enemigo de César. ${ }^{122}$ Por otro lado, tampoco las alianzas políticas eran inamovibles, incluso en las clientelae, como demuestra el propio Balbo el Mayor de Gades, ${ }^{123}$ y los Pompeii itucitanos, tras la deductio colonial de época augustea, alcanzaron importantes magistraturas en las dos ramas familiares, con el protagonismo de M. Pompeius Icstnis y Cn. Pompeius Afer, respectivamente. A nuestro juicio esta hipótesis explicaría las dudas expresadas por L. Amela en relación a estos dos magistrados itucitanos y su relación con Cneo Pompeyo. ${ }^{124}$ Es también posible que en aquellos momentos se quebrara aquella familia de origen indígena y "romanizada", si los dos Pompeii citados no tuvieron descendencia, pues ni aparecen otras urnas de descendientes de ambos ni volvemos a encontrar ningún otro documento que nos hable de los Pompeii en Torreparedones, aunque esto segundo no es -lógicamente-determinante.

Entre los personajes importantes documentados en la colonia podemos destacar diferentes individuos y familias. En primer lugar, debe referirse a Pontius, veterano de la Legio XXXIII, que es considerado como uno de los primeros colonos de la deductio augustea. ${ }^{125}$ Además, a M. Iunius M. f. Gal. Marcellus, tal como reza en la inscripción en letras doradas del pavimento de la plaza forense, que había sido IIvir antes de su importante acción benefactora; pudo tener alguna vinculación con

\footnotetext{
121 Amela Valverde 2002.

122 Vid., en general, Pina Polo 2019.

123 Pina Polo 2008.

124 Amela Valverde 2004, 80.

125 Ventura Villanueva 2012; 2014a, 31-32; 2014 b (=AE 2016, 741).
} 
la familia de Iunia Insghana, la mujer de Q. Pompeius Velaunis, aunque M. Iunius Marcellus se sitúa ya en un momento posterior, bajo el reinado de Tiberio. ${ }^{126}$ En el período julio-claudio también hay que citar a M. Calpurnius, que sería "capostípite de otra familia de colonos de la élite local" ${ }^{227}$ y que construyó de su dinero un arco y unas termas; tuvo libertos, uno de los cuales fue séviro augustal. ${ }^{128}$ Asimismo, destaca Laeta, de la gens Iulia, que fue sacerdos Divae Augustae, en una fecha posterior al 42 d.C., en que se divinizó a Livia. ${ }^{129}$ Además, se documenta el sacerdos de la diosa Salus, L. Cornelius Q. f. Campanus, hacia mediados del siglo I d.C. ${ }^{130}$ Importantes fueron los Mummii itucitanos, con estatuas de bronce dedicadas en el foro a L. Mummius, a su mujer - de nombre desconocido- y a su hija Mummia, pero ya durante época flavia; a un descendiente de estos, llamado $Q$. Mummius $L$. $f$. Gal. Gallus, se le dedicó otra estatua en el foro a comienzos del siglo II d.C.. ${ }^{131}$ y, finalmente, una vinculación familiar con estos Mummii itucitanos debió de tener el patriciense L. Iulius Gallus Mummianus ${ }^{132}$ según denota su nombre. ${ }^{133}$

\section{Conclusiones}

Como se dijo, en Ituci no se han documentado epigráficamente otros miembros de la familia Pompeia. Sin embargo, su tumba, construida en la necrópolis norte, muy cerca de la puerta septentrional urbana, demostraba la relevancia familiar alcanzada a lo largo del siglo I a.C.; ello se plasmaba en la nueva comunidad colonial, conformada a fines de la centuria, en cuyo álbum ciudadano debieron incluirse los dos duoviros. Se ha establecido así una propuesta de stemma de esta familia itucitana, vinculada originalmente a la política de promoción romana que protagonizó Pompeyo el Grande en Hispania y que -como se ha dicho suficientemente por todos los que se han acercado a su estudio desde el siglo XIX hasta hoy- es el conjunto epigráfico de carácter familiar más completo y de mayor importancia de la epigrafía hispanorromana en orden a analizar el proceso de "romanización" de las elites indígenas.

El nuevo stemma que establecemos, que remonta el origen familiar a fines del siglo II a.C. y lo lleva hasta los primeros decenios del siglo I d.C., durante un siglo $\mathrm{y}$ varias décadas, hace a nuestro juicio más atractivo y significativo este excepcional documento histórico, arqueológico y epigráfico, descubierto en las tierras del "cortijo de las Vírgenes" de Baena en 1833. Se trataría, pues, de una familia indígena, de raigambre turdetana, que alcanzó altas cotas de poder cívico en la nueva comunidad promocionada en época de Augusto, a pesar de su antigua vinculación a la clientela de Cneo Pompeyo el Grande. El nombre de la familia Pompeia, que se mantuvo en el tiempo, proclamaba aquel antiguo vínculo, pero a la vez la antigüedad de la ciudadanía romana de su linaje, que se entrelazaba con el de los antecesores indígenas, cuyos restos debieron ser trasladados a la nueva tumba. Todo

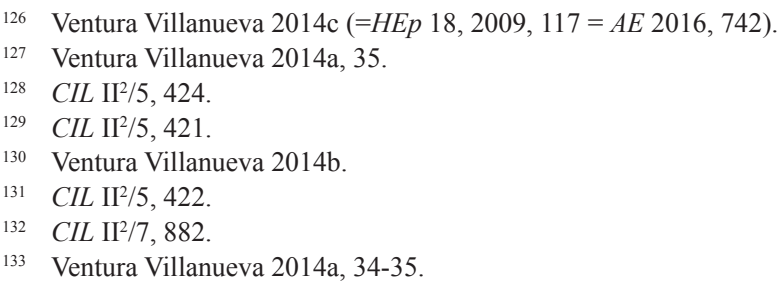


ello justificaba, además, el uso habitual de antiguos nombres familiares turdetanos en los cognomina de los últimos miembros; el caso del IIvir M. Pompeius Icstnis es significativo, pues, aunque su hermano mayor ya había adquirido un cognomen latino, Sabinus, él -hermano menor- mantiene uno indígena, al igual que su padre -a pesar de que este sí era el primogénito en la generación anterior-, que llevaba como cognomen el nombre Velaunis de su tatarabuelo, si consideramos válido el stemma familiar propuesto en este trabajo.

\section{Referencias bibliográficas}

Abascal Palazón, J. M. (1994): Los nombres personales en las inscripciones latinas de Hispania (=Anejos de Antigüedad y Cristianismo II), Murcia.

Albertos Firmat, $M^{\mathrm{a}}$ L. (1966): La onomástica personal primitiva de Hispania Tarraconense y Bética (=Publicaciones del Colegio trilingüe de la Universidad de Salamanca. Theses et studia philologica Salmanticensia 13), Salamanca.

Amela Valverde, L.

(2000): "Cneo Pompeyo hijo en Hispania antes de la batalla de Munda", ETF, Serie II. $H^{a}$ Antigua 13, 357-390 (https://doi.org/10.5944/etfii.13.2000.4381).

(2002): Las clientelas de Cneo Pompeyo magno en Hispania (=Universitat de Barcelona. Col·lecció Instrumenta 13), Barcelona.

(2004): "Las concesiones de ciudadanía romana: Pompeyo Magno e Hispania", L'Antiquité classique 73, 47-107 (https://doi.org/10.3406/antiq.2004.2537).

(2011): "Los Pompeii del Sepulcro de los Pompeyos (Torreparedones, Castro del Río, Baena, prov. Córdoba)", Myrtia 26, 27-41.

Beltrán Fortes, J.

(2000): "Mausoleos romanos de Torreparedones (Castro del Río/Baena, Córdoba): sobre la 'tumba de los Pompeyos' y otro posible sepulcro monumental”, Habis 31, 113-136.

(2008): "La arqueología cesariana de la provincia Hispania Ulterior", [en] García-Bellido - Mostalac - Jiménez (eds.), 2008, 67-83.

(2010): "El estudio arqueológico de la Tumba de los Pompeyos", [en] Beltrán Fortes et alii, 2010, 75-140.

(2014a): "La necrópolis norte", [en] Márquez et alii (eds.), 2014, 116-123.

(2014b): "Identidades cívicas en época romana republicana y altoimperial (ss. II a. C. - I d. C.) en la Hispania meridional. Los antiguos territorios de la Turdetania y la Oretania: algunas consideraciones sobre la escultura funeraria como tema de análisis", [en] T. Tortosa (ed.), Diálogo de identidades. Bajo el prisma de las manifestaciones religiosas en el ámbito mediterráneo (s. III a.C.-s. I d.C.), (=Anejos de AEspA LXXII), Mérida, 251-273.

(2017): "El mundo funerario augusteo en la Hispania meridional. Una aproximación arqueológica", [en] Mangas - Mayorgas (eds.), 2017, 791-808 (https://doi.org/doi. org/10.5209/GERI.56174).

Beltrán Fortes, J. - Maier, Allende, J. - Miranda Valdés, J. - Morena López, J. A. - Rodríguez Oliva, P. (2010): El mausoleo de los Pompeyos de Torreparedones (Baena. Córdoba). Análisis historiográfico y arqueológico (=Salsum 1), Madrid-Córdoba.

Beltrán Fortes, J. - Morena López, J. A. (2018): “Dos nuevos monumenta de la necrópolis norte de Torreparedones (Baena, Córdoba)", AEspA 91, 7-38 (https://doi.org/10.3989/ aespa.091.018.001). 
Beltrán Lloris, F. - Pina Polo, F. (2013): “Clientela y patronos en Hispania”, [en] J. López Vilar (ed.), Tarraco bienal. Actes. 1er Congrés Internacional d'Arqueologia i Món Antic. Govern i Societat a la Hispània Romana. Novetats Epigràfiques. Homenatge a Géza Alföldy, Tarragona, 51-61.

CIL II: Hübner, E. (ed.), (1869, 1892): Corpus Inscriptionum Latinarum II. Inscriptiones Hispaniae Latinae, Berolini; Supplementum, Berolini.

CIL II²/5: Stylow, A. U - Atencia Páez, R. - González Fernández, J. - González Román, C. - Pastor Muñoz, M. - Rodríguez Oliva, P. (eds.), (adiuuantibus H. Gimeno Pascual - M. Ruppert - M. G. Schmidt), (1998): Corpus inscriptionum Latinarum II. Inscriptiones Hispaniae Latinae. Editio altera. Pars V. Conventus Astigitanus, Berlin-New York.

CIL II2/7: Stylow, A. U (ed.), (1995): Corpus inscriptionum Latinarum II. Inscriptiones Hispaniae Latinae. Editio altera. Pars VII. Conventus Cordubensis, Berlin-New York.

Corte y Ruano, M. de la (1839): “Antigüedades españolas. Descubrimientos de Baena", Semanario Pintoresco Español 40 (6 de octubre), 318-319; 41 (15 de octubre), 326-328; 45 (10 de noviembre), 356-359; 50 (15 de diciembre), 398-399; 51 (22 de diciembre), 401-403.

Cunliffe, B. W. - Fernández Castro, Mª C. (1999): The Guadajoz Project. Andalucia in the First Millenium B.C. Volume 1. Torreparedones and Its Hinterland (=Oxford University Committee for Archaeology. Monograph 47), Oxford.

Feijoo, B. J. (1730): Teatro Crítico Universal, tomo IV, Madrid.

Fernández Castro, M ${ }^{\mathrm{a}}$ C. - Cunliffe, B. W. (2002): El yacimiento y el santuario de Torreparedones. Un lugar arqueológico preferente en la campiña de Córdoba (=BAR International Series 1030), Oxford.

Galsterer, H. (1971): Untersuchungen zum römischen Städtewesen auf der iberischen Halbinsel, (= Madrider Forschungen 8), Berlin.

García-Bellido, Ma P. - Mostalac, A. - Jiménez, A. (eds.), (2008): Del imperium de Pompeyo a la auctoritas de Augusto. Homenaje a Michael Grant (=Anejos de AEspA XLVII), Madrid.

González Román, C. (2017): “Augusto y las colonias de la Hispania meridional”, [en] Mangas - Mayorgas (eds.), 2017, 349-370 (https://doi.org/10.5209/GERI.56151).

Hübner, E.

(1861): “Antichità della Spagna. V. Monumenti romani in Andalusia", Bullettino dell'Istituto di Correspondenza Archeologica per l'anno 1861, Roma, 232.

(1885): Exempla scripturae epigraphicae Latinae a Caesaris dictatoris norte ad aetatem Iustiniani (Auctarium Corporis Inscriptionum Latinarum), Berolini (=Exempla).

López Castro, J. L. - Belmonte Marín, J. A. (2012): "Pervivencias de la antroponimia fenicia en época romana en la Península Ibérica", [en] B. Mora Serrano - G. Cruz Andreotti (eds.), La etapa neopúnica en Hispania y el Mediterráneo centro occidental: identidades compartidas (=Editorial Universidad de Sevilla. Historia y Geografía 246), Sevilla, 141164.

Maier Allende, J. (2010): "El mausoleo de los Pompeyos en su contexto histórico e historiográfico", [en] Beltrán Fortes et alii, 2010, 29-74.

Maier Allende, J. - Beltrán Fortes, J. (2010): “Apéndice documental”, [en] Beltrán Fortes et alii, 2010, 209-354.

Maier Allende, J. - Salas Álvarez, J. de la A. (2007): "Los inspectores de antigüedades de la Real Academia de la Historia en Andalucía”, [en] M. Belén Deamos - J. Beltrán Fortes (eds.), Las instituciones en el origen y desarrollo de la Arqueología en España (=Spal Monografías X), Sevilla, 175-238. 
Mangas, J. - Mayorgas, A. (eds.), (2017): La Hispania de Augusto (=Gerión 35), Madrid. Márquez, C. - Morena, J. A. - Córdoba, R. - Ventura, Á. (eds.), (2014): Torreparedones. Investigaciones arqueológicas (2006-2012), Córdoba.

Mérimée, P. (1844): "Inscriptions romaines de Baena", Revue Archéologique 1, 176-181.

Miranda Valdés, J. (2005): Aureliano Fernández-Guerra (1816-1894). Un romántico, escritor y anticuario (=Publicaciones del Gabinete de Antigüedades de la Real Academia de la Historia. Antiquaria Hispanica 10), Madrid.

Morena López, J. A.

(2010): "Investigaciones recientes en Torreparedones: prospección geofísica y excavaciones en el santuario y puerta oriental", [en] Beltrán Fortes et alii, 2010, 171-207. (2014): "El santuario ibero-romano", [en] Márquez et alii (eds.), 2014, 47-56.

(2019): Las santas Nunilo y Alodia ¿mártires mozárabes cordobesas?. A propósito del descubrimiento y excavación de la Ermita de las Virgenes de Castro el Viejo (Torreparedones, Baena-Córdoba), (=Historia y patrimonio Baenense 4), Córdoba.

Pina Polo, F.

(2008): "Hispania of Caesar and Pompey. A conflict of clientelae?", [en] García-Bellido - Mostalac - Jiménez (eds.), 2008, 41-48.

(2015): "Foreign Clientelae Revisited: A Methodological Critique", [en] M. Jehne F. Pina (eds.), Foreign clientelae in the Roman Empire. A Reconsideration (=Historia, Einzelschriften 238), Stuttgart, 19-42.

(2019): "Losers in the Civil War between Caesarians and Pompeians. Punishment and Survival", [en] K.-J. Hölkeskamp - H. Bech (eds.), Verlierer und Aussteiger in der 'Konkurrenz unter Anwesenden'. Agonalität in der politischen Kultur des antiken Rom, Stuttgart, 147-168.

Rodríguez de Berlanga, M. (1881): Los bronces de Lascuta, Bonanza y Aljustrel, Málaga.

Rodríguez Oliva, P.

(1993-1994): "Sobre algunos tipos de urnas cinerarias de la provincia Baetica y notas a propósito de la necrópolis de la calle Andrés Pérez de Málaga", Mainake 15-16, 223-242. (1999): "Incineración/inhumación: un milenio de prácticas funerarias en los territorios meridionales de la Península Ibérica", [en] J. Beltrán Fortes, Los sarcófagos romanos de la Bética con decoración de tema pagano, Málaga, v-lxii.

(2001): "Urnas cinerarias de un sepulcro familiar de época romana de Torredonjimeno (Jaén)”, Baetica 23, 363-385 (https://doi.org/10.24310/BAETICA.2001.v0i23.437).

(2002): "Talleres locales de urnas cinerarias y de sarcófagos en la Prouincia Hispania Ulterior Baetica", [en] D. Vaquerizo (ed.), Espacios y usos funerarios en el Occidente Romano, Córdoba, vol. I, 259-312.

(2010): "Las urnas del mausoleo de los Pompeyos", [en] Beltrán Fortes et alii, 2010, 141170.

Santos Yanguas, J. - Hoces de la Guardia Bermejo, Á. L. - del Hoyo, J. (2005): Epigrafía romana de Segovia y su provincia, Segovia.

Stylow, A. U. - Gimeno Pascual, H. (2004): "Emil Hübner”, [en] M. Ayarzagüena - G. Mora (coords.), Pioneros de la Arqueología en España del siglo XVI a 1912 (=Zona Arqueológica 3), Alcalá de Henares, 333-340.

Thouvenot, R. (1940): Essai sur la province romaine de Bétique (=Bibliothèque des Écoles françaises d'Athenes et de Rome 149), Paris.

TIR J-30: VV.AA. (2001): Tabula Imperii Romani. J-30: Valencia, Madrid.

Tristell, F. J. - López, I. (2014): "La necrópolis oriental”, [en] Márquez et alii (eds.), 2014, 111-115. 
Valverde y Perales, F. (1903): Historia de la Villa de Baena, Toledo.

Ventura Villanueva, Á.

(2012): "Nuevo descubrimiento epigráfico en Torreparedones", Ituci 2, 36-40.

(2014a): "La ocupación del territorio y la ciudad en época romana", [en] Márquez et alii (eds.), 2014, 29-38.

(2014b): "Culto a la Salud en Torreparedones", Ituci 4, 52-55.

(2014c): "El foro", [en] Márquez et alii (eds.), 2014, 69-86. 